\title{
Synthesis of some new derivatives of thiazolopyrimidines and hydrolysis of its arylidene derivative
}

\author{
H NAGARAJAIAH ${ }^{\mathrm{a}}$, IMTIYAZ AHMED M KHAZI ${ }^{\mathrm{b}}$ and NOOR SHAHINA BEGUM ${ }^{\mathrm{a}, *}$ \\ ${ }^{a}$ Department of Chemistry, Bangalore University, Central College Campus, Bangalore 560001, India \\ ${ }^{b}$ Department of Chemistry, Karnatak University, Dharwad 580003, India \\ e-mail:noorsb05@gmail.com; noorsb@rediffmail.com
}

MS received 16 May 2014; revised 12 September 2014; accepted 7 October 2014

\begin{abstract}
A new ammonium acetate-assisted, convenient and efficient procedure for the synthesis of arylidene derivatives of thiazolopyrimidine is described. The main advantages of this protocol is that it is economical, short reaction time, commonly available chemicals, and ease of isolation of products. In addition, a new series of thiazole-fused pyrimidines were synthesized and hydrolysis of one of its arylidene derivative studied. All the compounds were characterized by analytical and spectroscopic methods. Further, the structure of hydrolyzed product and two other compounds were confirmed by X-ray crystal structure analysis. The crystal structures are stabilized by intermolecular C-H. .O , C-H. .N, C-H. . $\pi$ and $\pi \ldots \pi$ weak interactions. The anti-microbial screening was done on the compounds in order to test their anti-bacterial and anti-fungal activities.
\end{abstract}

Keywords. Thiazolo[3,2-a]pyrimidines; hydrolysis of arylidene derivative; crystal structure; anti-microbial activity.

\section{Introduction}

Heterocycles containing sulphur and nitrogen are of great interest because they constitute an important class of natural and synthetic organic molecules, many of which exhibit useful biological activity. One such heterocyclic class is thiazolopyrimidines. These have generated interest in recent years due to their biological and pharmaceutical activities. These ring systems have shown anti-microbial, ${ }^{1-4}$ anti-malarial, ${ }^{5}$ anti-inflammatory, ${ }^{6,7}$ anti-oxidant, ${ }^{6}$ anti-nociceptive ${ }^{7}$ and antitubercular ${ }^{8}$ activity. In addition, they have been reported to possess anti-tumour activity ${ }^{9,10}$ and have also shown to possess anti-parkinsonian and anti-proliferative properties. ${ }^{11}$

In view of all these observations, we have undertaken the synthesis of some new derivatives of thiazolo $[3,2-a]$ pyrimidines. The traditional methods ${ }^{7,12-14}$ to synthesize arylidene derivative involve the use of $1: 1$ mixture of acetic acid and acetic anhydride in presence of sodium acetate. But this method is not satisfactory with regard to the isolation of the products and also due to the drastic reaction conditions that are employed. To overcome this limitation, we have developed a new protocol for the synthesis of arylidene derivative of thiazolopyrimidines using readily available, inexpensive and environment-friendly catalysts. We have made

\footnotetext{
*For correspondence
}

use of ammonium acetate under warm condition with ethanol as a solvent medium. It is a convenient and fast protocol, although the synthetic route followed is a conventional one. However, the duration of the reaction is very short, as it goes to completion in $10 \mathrm{~min}$. This is yet another advantage of the present protocol.

In continuation of our work with thiazolopyrimidines, we report herein the synthesis of some new derivatives and a tricyclic thiazolopyrimidine. It has been observed that the hydrolysis of arylidene derivative of thiazolopyrimidine occurs via rupture of imine bond under acidic condition. In this paper, the mechanism for hydrolysis has been proposed. Some of these derivatives exhibit promising anti-microbial activities. We have presented here the crystal structure analysis of the two derivatives. The structure analysis was undertaken to determine the configuration and conformation of the molecule and the orientation of the substituents around the thiazolopyrimidine framework.

\section{Experimental}

\subsection{Materials and methods}

All the chemicals were purchased from S D Fine and Spectrochem used as received without further purification. Melting point apparatus was used to determine the melting point in open capillaries and are uncorrected. IR spectra were recorded on Nicolet Impact 400D FT-IR 
spectrophotometer using $\mathrm{KBr}$ pellets. Bruker $400 \mathrm{MHz}$ FT-NMR spectrometer was used to record ${ }^{1} \mathrm{H}$ and ${ }^{13} \mathrm{C}$ NMR in $\mathrm{CDCl}_{3}$ and DMSO- $d_{6}$ with TMS as internal standard. The reactions and purity of the products were monitored by TLC silica gel plates. Mass spectra were recorded on LC-MSD-Trap-SL spectrometer and elemental analyses were carried out using CHNS Elimentar (Vario-micro cube).

\subsection{Procedure for the synthesis of compounds $2(\boldsymbol{a}-\boldsymbol{d})$}

A mixture of ethyl 3,5-dihydro-7-methyl-3-oxo-5phenyl-2 $H$-thiazolo[3,2-a]pyrimidine-6-carboxylate (1a/1d/1e) (10 mmol), aromatic aldehydes $(10 \mathrm{mmol})$ and catalytic amount of ammonium acetate in ethanol $(30 \mathrm{~mL})$ was warmed for 5-10 min with constant stirring. The reaction mixture was allowed to stand at room temperature for $30 \mathrm{~min}$. The solid thus separated was filtered and washed with water and recrystsallized from ethanol to afford yellow compound with good yield $82-87 \%$.

2.2a (2Z)-Ethyl 2-benzylidene-3,5-dihydro-7-methyl3-oxo-5-phenyl-2H-thiazolo[3,2-a] pyri-midine-6-carboxylate (2a): Yellow solid, yield 87\%, M.p.: 178$179{ }^{\circ} \mathrm{C}$. IR $(\mathrm{KBr}) v \mathrm{~cm}^{-1}: 2978(\mathrm{CH}), 1711(\mathrm{C}=\mathrm{O}), 1608$ $(\mathrm{C}=\mathrm{C}), 1484(\mathrm{C}=\mathrm{N}), 1169(\mathrm{C}-\mathrm{O}) .{ }^{1} \mathrm{H} \mathrm{NMR}\left(300 \mathrm{MH}_{\mathrm{Z}}\right.$, $\left.\mathrm{CDCl}_{3}\right) \delta$ ppm: $1.18\left(\mathrm{t}, J=7.2 \mathrm{~Hz}, 3 \mathrm{H}, \mathrm{CH}_{2} \mathrm{CH}_{3}\right), 2.52$ (s, $\left.3 \mathrm{H}, \mathrm{CH}_{3}\right), 4.11$ (q, J=7.2 Hz, $2 \mathrm{H}, \mathrm{CH}_{2} \mathrm{CH}_{3}$ ), 6.22 (s, 1H, C5-H), 7.26-7.45 (m, 10H, ArH). 7.73(s, 1H, arylidene-H). ${ }^{13} \mathrm{C} \mathrm{NMR}\left(300 \mathrm{MH}_{\mathrm{Z}}, \mathrm{CDCl}_{3}\right) \delta \mathrm{ppm}$ : $14.98,23.42$, 55.13, 60.35, 102.08, 108.88, 114.16, $127.41,128.15,129.62,130.96,132.43,134.09$, $144.51,154.62,159.62,163.14,165.62,167.73$. \%CHNS found (calc): C 68.30 (68.41), H 4.98 (5.13), N 6.93 (6.82), S 7.93 (8.13).

2.2b (2Z)-Methyl 2-(3-cyanobenzylidene)-3,5-dihydro5-(4-hydroxyphenyl)-7-methyl-3-oxo-2H-thiazolo[3,2a]pyrimidine-6-carboxylate (2b): Yellow solid, yield 84\%, M.p.:234-235 ${ }^{\circ}$ C. IR (KBr) $v \mathrm{~cm}^{-1}: 2987(\mathrm{CH})$, $1698(\mathrm{C}=\mathrm{O}), 1603(\mathrm{C}=\mathrm{C}), 1486(\mathrm{C}=\mathrm{N}), 1231(\mathrm{C}-\mathrm{O})$. ${ }^{1} \mathrm{H}$ NMR $\left(400 \mathrm{MH}_{\mathrm{Z}}\right.$, DMSO- $\left.d_{6}\right) \delta$ ppm: $2.38(\mathrm{~S}, 3 \mathrm{H}$, $\left.\mathrm{CH}_{3}\right), 3.60$ (s, 3H, $\left.\mathrm{OCH}_{3}\right), 5.96(\mathrm{~s}, 1 \mathrm{H}, \mathrm{C} 5-\mathrm{H}), 6.95-$ 7.95 (m, 9H, Ar-H), 9.58 (s, 1H, Ar-OH). ${ }^{13} \mathrm{C}$ NMR (400 $\mathrm{MH}_{\mathrm{Z}}$, DMSO- $\left.d_{6}\right) \delta$ ppm: 23.31, 54.86, 61.15, $100.14,122.96,127.15,128.4-137.63,141.04,145.78$, 153.04, 164.99, 165.69, 167.47. Mass (m/z): 432.22 $[\mathrm{M}+\mathrm{H}]^{+} . \% \mathrm{CHNS}$ found (calc): C 64.03 (64.32), H 3.97 (3.76), N 9.74 (9.63), S 7.43 (7.59).

2.2c 4-((1Z)-(6-(ethoxycarbonyl)-5-(4-hydroxyphenyl)-7 -methyl-3-oxo-3H-thiazolo[3,2-a] pyrimidin-2(5H)-ylidene)methyl)benzoic acid (2c): Yellow solid, yield
82\%, M.p.: $241-242^{\circ} \mathrm{C}$. IR (KBr) $v \mathrm{~cm}^{-1}: 2981(\mathrm{CH})$, $1698(\mathrm{C}=\mathrm{O}), 1599(\mathrm{C}=\mathrm{C}), 1491(\mathrm{C}=\mathrm{N}), 1215(\mathrm{C}-\mathrm{O})$. ${ }^{1} \mathrm{H}$ NMR $\left(400 \mathrm{MH}_{\mathrm{Z}}, \mathrm{CDCl}_{3}\right) \delta \mathrm{ppm}: 1.18(\mathrm{t}, J=7.2$ $\mathrm{Hz}, 3 \mathrm{H}, \mathrm{CH}_{2} \mathrm{CH}_{3}$ ), 2.37 (s, 3H, $\mathrm{CH}_{3}$ ), 4.09 (q, $J=7.2$ $\left.\mathrm{Hz}, 2 \mathrm{H}, \mathrm{CH}_{2} \mathrm{CH}_{3}\right), 6.19$ (s, 1H, C5-H), 7.26-7.74 (m, 9H, Ar-H), 9.62 (s, 1H, OH), 13.10 (s, 1H, COOH).

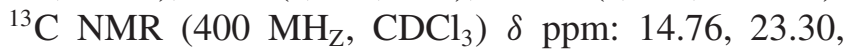
54.86, 60.09, 100.14, 109.91, 122.96, 127.15-141.04, $145.28,153.04,156.04,164.99,165.69,166.23$, 167.47. \%CHNS found (calc): C 62.06 (62.12), H 4.34 (4.52), N 6.03 (6.31), S 6.90 (6.61).

2.2d (2Z)-methyl 2-(3-fluorobenzylidene)-3,5-dihydro5-(4-hydroxyphenyl)-7-methyl-3-oxo-2H-thiazolo[3,2a]pyrimidine-6-carboxylate $(\mathbf{2 d})$ : Yellow solid, yield 84\%, M.p.: 286-287 C. IR (KBr) $v \mathrm{~cm}^{-1}: 2976(\mathrm{CH})$, $1701(\mathrm{C}=\mathrm{O}), 1598(\mathrm{C}=\mathrm{C}), 1497(\mathrm{C}=\mathrm{N}), 1192(\mathrm{C}-\mathrm{O})$. ${ }^{1} \mathrm{H} \mathrm{NMR}\left(400 \mathrm{MH}_{\mathrm{Z}}, \mathrm{CDCl}_{3}\right) \delta \mathrm{ppm}: 2.36\left(\mathrm{~S}, 3 \mathrm{H}, \mathrm{CH}_{3}\right)$, $3.67\left(\mathrm{~s}, 3 \mathrm{H}, \mathrm{OCH}_{3}\right), 6.02(\mathrm{~s}, 1 \mathrm{H}, \mathrm{C} 5-\mathrm{H}), 6.75-7.83$ (m, 9H, Ar-H), 9.60 (s, 1H, OH). ${ }^{13} \mathrm{C}$ NMR $\left(400 \mathrm{MH}_{\mathrm{Z}}\right.$, $\left.\mathrm{CDCl}_{3}\right) \delta$ ppm: 23.26, 55.44, 60.12, 100.14, 116.29, 122.96, 127.15, 128.4-137.63, 141.04, 145.78, 154.03, $162.31,164.72,165.59,167.42$. \%CHNS found (calc): C 62.25 (62.42), H 4.04 (4.06), N 6.60 (6.83), S 7.55 (7.59).

\subsection{Procedure for the hydrolyzed compound $\mathbf{3}$}

2.3a Method 1: Compound 1a was refluxed with benzaldehyde in presence of ammonium acetate in acetic acid for 5-6h with constant stirring. The reaction mixture was allowed to stand at room temperature overnight. The solid thus separated was filtered, washed with water and recrystallized from ethanol to afford pale yellow crystals in good yield (82\%).

2.3b Method 2: A mixture of compound 2a and catalytic amount of conc. $\mathrm{HCl}$ in ethanol $(100 \mathrm{~mL})$ was refluxed for 5-6h with constant stirring. The reaction mixture was allowed to stand room temperature overnight. The solid thus separated was filtered, washed with water and recrystsallized from ethanol to afford good quality crystals (yield 80\%).

2.3c (Z)-5-Benzylidenethiazolidine-2,4-dione(3): Colourless solid, yield 82\%, M.p.: $264-265^{\circ} \mathrm{C}$. IR (KBr) $v$ $\mathrm{cm}^{-1}$ : $3145(\mathrm{NH}), 3037(\mathrm{CH}), 1739$ (SCONH), $1691(\mathrm{CONH}), 1606(\mathrm{C}=\mathrm{C}), 1336(\mathrm{C}-\mathrm{N}) .{ }^{1} \mathrm{H}$ NMR $\left(300 \mathrm{MH}_{\mathrm{Z}}\right.$, DMSO- $\left.d_{6}\right) \delta \mathrm{ppm}: 7.42-7.58(\mathrm{~m}, 5 \mathrm{H}, \mathrm{Ar}-\mathrm{H})$, $7.75(\mathrm{~s}, 1 \mathrm{H}$, arylidene-H), $12.58(\mathrm{~s}, 1 \mathrm{H}, \mathrm{NH}), \% \mathrm{CHNS}$ found (calc): C 58.52 (58.63), H 3.44 (3.23), N 6.82 (6.67), S 15.62 (15.67). 


\subsection{General procedure for the synthesis compounds $4 a$ and $4 b$}

A mixture of ethyl 3,5-dihydro-7-methyl-3-oxo-5substituted phenyl-2 $H$-thiazolo[3,2- $a$ ]pyrimidine-6carboxylate $(5 \mathrm{mmol})$, morpholine $(6 \mathrm{mmol})$, formalin $(1 \mathrm{~mL})$ and acetic acid $(1 \mathrm{~mL})$ in methanol $(20 \mathrm{~mL})$ was refluxed for $8 \mathrm{~h}$ (monitored by TLC). Reaction mixture was diluted with water and extracted with chloroform $(3 \times 30 \mathrm{~mL})$. The combined chloroform extract was washed with water $(3 \times 30 \mathrm{~mL})$ and dried over anhydrous sodium sulfate. The solvent was removed under vacuum and the residue was recrystallized from benzene and hexane mixture to yield colorless to yellow granules with good yield $82-87 \%$.

2.4a (2Z)-ethyl 3,5-dihydro-7-methyl-2-(morpholinomethyl)-3-oxo-5-phenyl-2H-thiazolo [3,2-a]pyrimidine6-carboxylate (4a): Pale yellow solid, yield 87\%, M.p.: 84-85 ${ }^{\circ}$ C. IR (KBr) $v \mathrm{~cm}^{-1}: 2982(\mathrm{CH}), 1711$ $(\mathrm{C}=\mathrm{O}), 1613 \quad(\mathrm{C}=\mathrm{C}), 1499 \quad(\mathrm{C}=\mathrm{N}), 1180 \quad(\mathrm{C}-\mathrm{O})$. ${ }^{1} \mathrm{H}$ NMR $\left(400 \mathrm{MH}_{\mathrm{Z}}, \mathrm{CDCl}_{3}\right) \delta$ ppm: $1.16(\mathrm{t}, J=7.2$ $\mathrm{Hz}, 3 \mathrm{H}, \mathrm{CH}_{2} \mathrm{CH}_{3}$ ), 2.38 (s, $\left.3 \mathrm{H}, \mathrm{CH}_{3}\right), 2.47$ (t, $J=4.5$ $\mathrm{Hz}, 4 \mathrm{H}, \mathrm{C}_{3}, \mathrm{C}_{5}-\mathrm{H}$, morpholine), $3.00(\mathrm{~d}, J=4.1 \mathrm{~Hz}$, $2 \mathrm{H}, \mathrm{CH}_{2}-\mathrm{N}$ ), $3.36(\mathrm{t}, J=4.3 \mathrm{~Hz}, 1 \mathrm{H}, \mathrm{S}-\mathrm{CH}), 3.63$ (t, J=4.3 Hz, 4H, $\mathrm{C}_{2}, \mathrm{C}_{6}-\mathrm{H}$, morpholine), 4.07 (q, $\left.J=7.2 \mathrm{~Hz}, 2 \mathrm{H}, \mathrm{CH}_{2} \mathrm{CH}_{3}\right), 5.99$ (s, $\left.1 \mathrm{H}, \mathrm{C} 5-\mathrm{H}\right), 7.26-$ $7.36(\mathrm{~m}, 5 \mathrm{H}, \mathrm{Ar}-\mathrm{H}) .{ }^{13} \mathrm{C}$ NMR $\left(400 \mathrm{MH}_{\mathrm{Z}}, \mathrm{CDCl}_{3}\right) \delta$ ppm: 14.06, 22.27, 50.48, 54.11, 55.37, 57.23, 59.19, 60.51, 101.16, 117.23, 127.9-136.32, 140.07, 144.98, $155.13,161.92,164.29,166.01,167.13 . \%$ CHNS found (calc): C 60.70 (60.49), H 6.06 (5.76), N 10.11 (10.33), S 7.72 (7.59).

$2.4 \mathrm{~b}$ (2Z)-ethyl 3,5-dihydro-5-(3-methoxyphenyl)-7methyl-2-(morpholinomethyl)-3-oxo-2H-thiazolo[3,2-a] pyrimidine-6-carboxylate (4b): Pale yellow solid, yield $82 \%$, M.p.: $88-89^{\circ} \mathrm{C}$. IR (KBr) $v \mathrm{~cm}^{-1}: 2996$ $(\mathrm{CH}), 1707(\mathrm{C}=\mathrm{O}), 1601(\mathrm{C}=\mathrm{C}), 1512(\mathrm{C}=\mathrm{N}), 1172$ (C-O). ${ }^{1} \mathrm{H}$ NMR $\left(400 \mathrm{MH}_{\mathrm{Z}}, \mathrm{CDCl}_{3}\right) \delta \mathrm{ppm}: 1.17(\mathrm{t}$, $\left.J=7.2 \mathrm{~Hz}, 3 \mathrm{H},-\mathrm{CH}_{2} \mathrm{CH}_{3}\right), 2.36\left(\mathrm{~s}, 3 \mathrm{H}, \mathrm{CH}_{3}\right), 2.47$ (t, J=4.5 Hz, 4H, $\mathrm{C}_{3}, \mathrm{C}_{5}-\mathrm{H}$, morpholine), 3.08 (d, $\left.J=4.1 \mathrm{~Hz}, 2 \mathrm{H}, \mathrm{CH}_{2}\right), 3.33(\mathrm{t}, J=4.3 \mathrm{~Hz}, 1 \mathrm{H}, \mathrm{S}-\mathrm{CH})$, 3.65 (t, $J=4.3 \mathrm{~Hz}, 4 \mathrm{H}, \mathrm{C}_{2}, \mathrm{C}_{6}-\mathrm{H}$, morpholine), 3.79 (s, $\left.3 \mathrm{H}, \mathrm{OCH}_{3}\right), 4.10\left(\mathrm{q}, \mathrm{J}=7.2 \mathrm{~Hz}, 2 \mathrm{H}, \mathrm{CH}_{2} \mathrm{CH}_{3}\right), 6.05$ (s, 1H, C5-H), 7.13-7.41 (m, 4H, Ar-H). ${ }^{13} \mathrm{C}$ NMR $\left(400 \mathrm{MH}_{\mathrm{Z}}, \mathrm{CDCl}_{3}\right) \delta$ ppm: 13.98, 22.19, 50.43, $54.17,55.90,57.71,59.42,60.18,61.41,100.43$, $119.19, \quad 126.36-138.50, \quad 140.57,144.02,155.19$, 161.92, 163.41, 165.97, 167.11. \%CHNS found (calc): C 59.31 (59.23), H 6.11 (6.37), N 9.43 (9.22), S 7.20 (7.47).
2.5 General procedure for the synthesis of compounds $5(a-d)$

A mixture of compound $\mathbf{1}(\mathbf{a}-\mathbf{d})(10 \mathrm{mmol})$ and DMFDMA $(5 \mathrm{~mL})$ was heated under reflux for $2 \mathrm{~h}$. The reaction mixture was triturated with ethanol to give a solid product that was collected by filtration and crystallized from ethanol to give compounds $\mathbf{5}(\mathbf{a}-\mathbf{d})$ as deep orange crystals with yield of $85-89 \%$.

2.5a 2-Dimethylaminomethylene-7-methyl-3-oxo-5phenyl-2,3-dihydro-5H-thiazolo[3,2-a]pyrimi -dine-6carboxylic acid ethyl ester (5a): Orange yellow solid, yield $87 \%$, M.p.: $204-205^{\circ} \mathrm{C}$. IR (KBr) $v \mathrm{~cm}^{-1}: 2983$ $(\mathrm{CH}), 1710(\mathrm{C}=\mathrm{O}), 1618(\mathrm{C}=\mathrm{C}), 1490(\mathrm{C}=\mathrm{N}), 1179$ (C-O). ${ }^{1} \mathrm{H}$ NMR $\left(400 \mathrm{MH}_{\mathrm{Z}}, \mathrm{CDCl}_{3}\right) \delta \mathrm{ppm}: 1.17(\mathrm{t}$, $\left.J=7.2 \mathrm{~Hz}, 3 \mathrm{H}, \mathrm{CH}_{2} \mathrm{CH}_{3}\right), 2.47$ (s, 3H, $\left.\mathrm{CH}_{3}\right), 3.10$ (s, $6 \mathrm{H}, 2 \mathrm{XCH}_{3}$ ), 4.08 (q, $J=7.2 \mathrm{~Hz}, 2 \mathrm{H}, \mathrm{CH}_{2} \mathrm{CH}_{3}$ ), 6.16 (s, 1H, C5-H), 7.19-7.39 (m, 5H, Ar-H), 7.49 (s, 1H, $\left.=\mathrm{CH}-\mathrm{NMe}_{2}\right) .{ }^{13} \mathrm{C} \mathrm{NMR}\left(400 \mathrm{MHz}, \mathrm{CDCl}_{3}\right) \delta \mathrm{ppm}$ : $14.14,23.02$, 54.87, 59.99, 86.06, 106.03, 127.82$128.34,141.71,145.73,154.32,166.05,166.15$. \%CHNS found (calc): C 61.44 (61.41), H 5.70 (5.76), N 11.31 (11.33), S 8.63 (8.59).

2.5b 2-Dimethylaminomethylene-5-(3-methoxy-phenyl)7-methyl-3-oxo-2,3-dihydro-5H-thiazolo[3,2-a]pyrimidine-6-carboxylic acid ethyl ester $(\mathbf{5 b})$ : Orange yellow solid, yield $89 \%$, M.p.: $181-182^{\circ} \mathrm{C}$. IR $(\mathrm{KBr}) v$ $\mathrm{cm}^{-1}$ : 3033, $2987(\mathrm{CH}), 1714(\mathrm{C}=\mathrm{O}), 1620(\mathrm{C}=\mathrm{C})$, $1499(\mathrm{C}=\mathrm{N}), 1173(\mathrm{C}-\mathrm{O}) .{ }^{1} \mathrm{H}$ NMR $\left(400 \mathrm{MH}_{\mathrm{Z}}\right.$, $\left.\mathrm{CDCl}_{3}\right) \delta$ ppm: $1.19\left(\mathrm{t}, J=7.2 \mathrm{~Hz}, 3 \mathrm{H}, \mathrm{CH}_{2} \mathrm{CH}_{3}\right), 2.47$ $\left(\mathrm{s}, 3 \mathrm{H}, \mathrm{CH}_{3}\right), 3.11\left(\mathrm{~s}, 6 \mathrm{H}, 2 \mathrm{XCH}_{3}\right), 3.75\left(\mathrm{~s}, 3 \mathrm{H}, \mathrm{OCH}_{3}\right)$, 4.09 (q, $\left.J=7.2 \mathrm{~Hz}, 2 \mathrm{H}, \mathrm{CH}_{2} \mathrm{CH}_{3}\right), 6.15$ (s, 1H, C5-H), 6.75-7.26 (m, 4H, Ar-H), $7.53\left(\mathrm{~s}, 1 \mathrm{H},=\mathrm{CH}-\mathrm{NMe}_{2}\right)$. ${ }^{13} \mathrm{C}$ NMR $\left(400 \mathrm{MHz}, \mathrm{CDCl}_{3}\right) \delta$ ppm: 14.19, 22.93, $54.59,60.06,61.32,86.43,106.27,127.85-128.54$, 140.36, 141.55, 145.82, 154.41, 165.89, 166.32. Mass $(\mathrm{m} / \mathrm{z}): 402.3[\mathrm{M}+\mathrm{H}]^{+}$. \%CHNS found (calc): C 59.83 (60.12), H 5.77 (5.76), N 10.47 (10.33), S 7.99 (7.95).

2.5c 2-Dimethylaminomethylene-5-(4-methoxy-phenyl) -7-methyl-3-oxo-2,3-dihydro-5H-thiazolo[3,2-a]pyrimidine-6-carboxylic acid ethyl ester (5c): Orange yellow solid, yield $85 \%$, M.p.: $165-167^{\circ} \mathrm{C}$. IR $(\mathrm{KBr}) v$ $\mathrm{cm}^{-1}: 3035,2996(\mathrm{CH}), 1711(\mathrm{C}=\mathrm{O}), 1600(\mathrm{C}=\mathrm{C})$, $1498(\mathrm{C}=\mathrm{N}), 1215(\mathrm{C}-\mathrm{O}) .{ }^{1} \mathrm{H}$ NMR $\left(400 \mathrm{MH}_{\mathrm{Z}}\right.$, $\left.\mathrm{CDCl}_{3}\right) \delta \mathrm{ppm}: 1.18\left(\mathrm{t}, J=7.2 \mathrm{~Hz}, 3 \mathrm{H},-\mathrm{CH}_{2} \mathrm{CH}_{3}\right)$, $2.51\left(\mathrm{~s}, 3 \mathrm{H}, \mathrm{CH}_{3}\right), 3.13\left(\mathrm{~s}, 6 \mathrm{H}, 2 \mathrm{XCH}_{3}\right), 3.75(\mathrm{~s}, 3 \mathrm{H}$, $\left.-\mathrm{OCH}_{3}\right), 4.09$ (q, J=7.2 Hz, 2H, $\left.\mathrm{CH}_{2} \mathrm{CH}_{3}\right), 6.14(\mathrm{~s}, 1 \mathrm{H}$, C5-H), 6.78-7.33 (m, 4H, Ar-H), $7.55(\mathrm{~s}, 1 \mathrm{H},=\mathrm{CH}-$ $\left.\mathrm{NMe}_{2}\right) .{ }^{13} \mathrm{C}$ NMR $\left(400 \mathrm{MHz}, \mathrm{CDCl}_{3}\right) \delta$ ppm: 14.03, 
$23.21,54.89,59.93,61.10,87.33,106.05,127.52$, $128.87,139.59,141.76,145.32,154.19,166.27$, 167.02. \%CHNS found (calc): C 59.83 (60.12), H 5.77 (5.76), N 10.47 (10.33), S 7.99 (7.95).

2.5d 2-Dimethylaminomethylene-5-(4-hydroxy-phenyl) -7-methyl-3-oxo-2,3-dihydro-5H-thiazolo[3,2-a]pyrimidine-6-carboxylic acid ethyl ester $(5 \boldsymbol{d})$ : Orange yellow solid, yield $87 \%$, M.p.: $280-281^{\circ} \mathrm{C}$. IR (KBr) $v \mathrm{~cm}^{-1}: 3321(\mathrm{OH}), 2979(\mathrm{CH}), 1712(\mathrm{C}=\mathrm{O}), 1623$ $(\mathrm{C}=\mathrm{C}), 1492(\mathrm{C}=\mathrm{N}), 1183(\mathrm{C}-\mathrm{O}) .{ }^{1} \mathrm{H} \mathrm{NMR}\left(400 \mathrm{MH}_{\mathrm{Z}}\right.$, $\left.\mathrm{CDCl}_{3}\right) \delta$ ppm: 1.21 (t, $\left.J=7.2 \mathrm{~Hz}, 3 \mathrm{H}, \mathrm{CH}_{2} \mathrm{CH}_{3}\right), 2.64$ $\left(\mathrm{s}, 3 \mathrm{H}, \mathrm{CH}_{3}\right), 3.22\left(\mathrm{~s}, 6 \mathrm{H}, 2 \mathrm{XCH}_{3}\right), 4.12(\mathrm{q}, J=7.2 \mathrm{~Hz}$, $\left.2 \mathrm{H}, \mathrm{CH}_{2} \mathrm{CH}_{3}\right), 6.13$ (s, 1H, C5-H), 6.74-7.09 (m, 4H, Ar-H), 7.59 (s, 1H, =CH-NMe $), 9.60(\mathrm{~s}, 1 \mathrm{H},-\mathrm{OH})$. ${ }^{13} \mathrm{C}$ NMR $\left(400 \mathrm{MHz}, \mathrm{CDCl}_{3}\right) \delta$ ppm: 13.90, 23.01, 54.47, 60.06, 86.88, 107.03, 124.72, 127.40, 143.76, $145.19,154.62,165.95,166.31$. \%CHNS found (calc): C 58.90 (58.76), H 5.46 (5.59), N 10.85 (10.63), S 8.28 (8.31).

\subsection{General procedure for the synthesis of compounds} $\mathbf{6} \boldsymbol{a}$ and $\mathbf{6 b}$

A mixture of 2-dimethylaminomethylene-7-methyl3-oxo-5-substituted phenyl-2,3-dihydro-5 $\mathrm{H}$-thiazolo $[3,2-a]$ pyrimidine-6-carboxylic acid ethyl ester ( $5 \mathrm{mmol}), 2$-amino benzoic acid $(5 \mathrm{mmol})$ and acetic acid $(1 \mathrm{~mL})$ in methanol $(30 \mathrm{~mL})$ was refluxed for $8 \mathrm{~h}$ (monitored by TLC). The excess methanol was removed under reduced pressure. The compound was diluted with water. The solid thus separated was filtered and dried to give yellow compound with $60-63 \%$ yield.

$2.6 \mathrm{a}$ 2-((1Z)-(6-(ethoxycarbonyl)-7-methyl-3-oxo-5phenyl-3H-thiazolo[3,2-a]pyrimidin-2 (5H)-ylidene)methy lamino)benzoic acid (6a): Yellow solid, yield 60\%, M.p.:244-245 ${ }^{\circ} \mathrm{C}$. IR (KBr) $v \mathrm{~cm}^{-1}$ : $3340(\mathrm{OH})$, 2994(CH), 1712 (ester $\mathrm{C}=\mathrm{O}), 1690(\mathrm{COOH}), 1510$ $(\mathrm{C}=\mathrm{C}), 1042(\mathrm{C}-\mathrm{O}) .{ }^{1} \mathrm{H}$ NMR $\left(400 \mathrm{MH}_{\mathrm{Z}}, \mathrm{DMSO}-d_{6}\right) \delta$ ppm: $1.10\left(\mathrm{t}, J=7.2 \mathrm{~Hz}, 3 \mathrm{H}, \mathrm{CH}_{2} \mathrm{CH}_{3}\right), 2.21(\mathrm{~s}, 3 \mathrm{H}$, $\left.\mathrm{CH}_{3}\right), 3.99$ (q, J=7.2 Hz, 2H, $\left.\mathrm{CH}_{2}\right), 5.72(\mathrm{~s}, 1 \mathrm{H}, \mathrm{C} 5-\mathrm{H})$, 6.63-8.03(m, 8H, Ar-H), 9.87 (d,1H, NH), 11.83(s, 1H, $\mathrm{COOH}) .{ }^{13} \mathrm{C}$ NMR $\left(400 \mathrm{MH}_{\mathrm{Z}}\right.$, DMSO- $\left.d_{6}\right) \delta$ ppm:14.02, $17.70,53.72$, 59.14, 112.10, 112.35, 114.44-132.25, $145.41,146.32,159.61,167.29$. \% CHNS found (calc): C 62.19 (62.34), H 4.57 (4.53), N 9.07 (8.88), S 6.92 (6.97).

$2.6 b \quad 2-(-(6-($ ethoxycarbonyl)-5-(3-methoxyphenyl)-7methyl-3-oxo-3H-thiazolo[3,2-a]pyrimi-din-2(5H)-yli- dene)methylamino)benzoic acid (6b): Yellow solid, yield 63\%, M.p.:220-221 ${ }^{\circ} \mathrm{C}$. IR (KBr) $v \mathrm{~cm}^{-1}: 3342$ (-OH), $2987(\mathrm{CH}), 1710$ (ester $\mathrm{C}=\mathrm{O}), 1691(\mathrm{COOH})$, $1503(\mathrm{C}=\mathrm{C}), 1052(\mathrm{C}-\mathrm{O}) .{ }^{1} \mathrm{H}$ NMR $\left(400 \mathrm{MH}_{\mathrm{Z}}\right.$, DMSO$\left.d_{6}\right) \delta$ ppm: $1.11\left(\mathrm{t}, J=7.2 \mathrm{~Hz}, 3 \mathrm{H}, \mathrm{CH}_{2} \mathrm{CH}_{3}\right), 2.23$ $\left(\mathrm{s}, 3 \mathrm{H}, \mathrm{CH}_{3}\right), 3.79\left(\mathrm{~s}, 3 \mathrm{H}, \mathrm{OCH}_{3}\right), 3.99(\mathrm{q}, J=7.2 \mathrm{~Hz}$, $\left.2 \mathrm{H}, \mathrm{CH}_{2}\right), 5.73$ (s, 1H, C5-H), 6.76-8.05(m, 9H, Ar-H), $9.88(\mathrm{~d}, 1 \mathrm{H}, \mathrm{NH}), 11.85(\mathrm{~s}, 1 \mathrm{H},-\mathrm{COOH}) .{ }^{13} \mathrm{C} \mathrm{NMR}$ $\left(400 \mathrm{MH}_{\mathrm{Z}}, \mathrm{DMSO}-d_{6}\right) \delta$ ppm:14.23, 17.68, 53.70, $55.25,59.15,112.10,112.35,115.26-134.39,144.54$, 146.30, 159.60, 167.20. \%CHNS found (calc): C 60.84 (60.99), H 4.70 (4.63), N 8.51 (8.67), S 6.50 (6.38).

\subsection{General procedure for the synthesis of compounds $7(a-f)$}

To a solution of $\mathbf{5 a} / \mathbf{5 b}(5 \mathrm{mmol})$ in ethanol $(30 \mathrm{~mL}) \mathrm{sec}-$ ondary amines like morpholine, piperidine and pyrrolidine $(5 \mathrm{mmol})$ was added and then refluxed for several hours. Completion of the reaction was monitored by TLC. The solid separated was filtered and dried to get the desired product.

2.7a 7-Methyl-2-morpholin-4-ylmethylene-3-oxo-5-phenyl-2,3-dihydro-5H-thiazolo[3,2-a] pyrimidine-6-carboxylic acid ethyl ester (7a): Pale orange yellow solid, yield $80 \%$, M.p.:221-222 ${ }^{\circ}$ C. IR (KBr) $v$ $\mathrm{cm}^{-1}: 2982(\mathrm{CH}), 1705(\mathrm{C}=\mathrm{O}), 1612(\mathrm{C}=\mathrm{C}), 1502$ $(\mathrm{C}=\mathrm{N}), 1192(\mathrm{C}-\mathrm{O}) .{ }^{1} \mathrm{H}$ NMR $\left(400 \mathrm{MH}_{\mathrm{Z}}, \mathrm{CDCl}_{3}\right) \delta$ ppm: 1.17 (t, $\left.J=7.2 \mathrm{~Hz}, 3 \mathrm{H}, \mathrm{CH}_{2} \mathrm{CH}_{3}\right), 2.50(\mathrm{~s}, 3 \mathrm{H}$, $\left.\mathrm{CH}_{3}\right), 3.45\left(\mathrm{t}, J=4.8 \mathrm{~Hz}, 4 \mathrm{H}, \mathrm{CH}_{2} \mathrm{CH}_{2}\right), 3.73(\mathrm{t}, J=4.8$ $\mathrm{Hz}, 4 \mathrm{H}, \mathrm{CH}_{2} \mathrm{CH}_{2}$ ), 4.09 (q, J=7.2 Hz, $2 \mathrm{H}, \mathrm{CH}_{2} \mathrm{CH}_{3}$ ), 6.17 (s, 1H, C5-H), 7.23-7.40 (m, 5H, Ar-H), 7.49 (s, $\left.1 \mathrm{H},=\mathrm{CH}-\mathrm{N}\left(\mathrm{CH}_{2}\right)_{2}\right) .{ }^{13} \mathrm{C}$ NMR $\left(400 \mathrm{MH}_{\mathrm{Z}}, \mathrm{CDCl}_{3}\right) \delta$ ppm: 14.16, 23.02, 55.57, 57.03, 59.89, 60.15, 100.18, $117.54,125.79-137.27,140.04,144.56,155.29$, $161.09,164.61,166.26,167.01$. \%CHNS found (calc): C 61.00 (61.10), H 5.61 (5.66), N 10.16 (10.31), S 7.75 (7.93).

2.7b 5-(3-Methoxy-phenyl)-7-methyl-2-morpholin-4ylmethylene-3-oxo-2,3-dihydro-5H-thia -zolo[3,2-a]pyrimidine-6-carboxylic acid ethyl ester (7b): Pale orange yellow solid, yield $78 \%$, M.p.:214-215 ${ }^{\circ} \mathrm{C}$. IR $(\mathrm{KBr}) v \mathrm{~cm}^{-1}:$ 3037, $2956(\mathrm{CH}), 1703(\mathrm{C}=\mathrm{O}), 1610$ $(\mathrm{C}=\mathrm{C}), 1501(\mathrm{C}=\mathrm{N}), 1198(\mathrm{C}-\mathrm{O}) .{ }^{1} \mathrm{H} \mathrm{NMR}\left(400 \mathrm{MH}_{\mathrm{Z}}\right.$, $\left.\mathrm{CDCl}_{3}\right) \delta$ ppm: $1.18\left(\mathrm{t}, J=7.2 \mathrm{~Hz}, 3 \mathrm{H}, \mathrm{CH}_{2} \mathrm{CH}_{3}\right), 2.51$ (s, 3H, $\mathrm{CH}_{3}$ ), 3.43 (t, J=4.8 Hz, 4H, $\mathrm{CH}_{2} \mathrm{CH}_{2}$ ), 3.73 (t, $\left.J=4.8 \mathrm{~Hz}, 4 \mathrm{H}, \mathrm{CH}_{2} \mathrm{CH}_{2}\right), 4.05(\mathrm{q}, J=7.2 \mathrm{~Hz}, 2 \mathrm{H}$, $\left.\mathrm{CH}_{2} \mathrm{CH}_{3}\right), 6.12$ (s, 1H, C5-H), 7.27-7.64 (m, 4H, Ar$\mathrm{H}), 7.51\left(\mathrm{~s}, 1 \mathrm{H},=\mathrm{CH}-\mathrm{N}\left(\mathrm{CH}_{2}\right)_{2}\right) .{ }^{13} \mathrm{C} \mathrm{NMR}\left(400 \mathrm{MH}_{\mathrm{Z}}\right.$, $\left.\mathrm{CDCl}_{3}\right) \delta$ ppm: 14.01, 23.12, 55.47, 57.17, 58.03, 
59.67, 60.18, 100.04, 119.21, 125.63-137.37, 140.16, $144.37,154.48,160.59,164.16,166.66,167.13$. \%CHNS found (calc): C 59.58 (59.62), H 9.47 (9.71), N 9.47 (9.38), S 7.23 (7.15).

2.7c 7-Methyl-3-oxo-5-phenyl-2-piperidin-1-ylmethylene-2,3-dihydro-5H-thiazolo[3,2-a] pyrimidine-6-carboxylic acid ethyl ester (7c): Pale orange red solid, yield 76\%, M.p.:242-243 ${ }^{\circ}$ C. IR ( $\left.\mathrm{KBr}\right) v \mathrm{~cm}^{-1}: 2974$ $(\mathrm{CH}), 1701(\mathrm{C}=\mathrm{O}), 1605(\mathrm{C}=\mathrm{C}), 1495(\mathrm{C}=\mathrm{N}), 1188$ (C-O). ${ }^{1} \mathrm{H}$ NMR (400 $\left.\mathrm{MH}_{\mathrm{Z}}, \mathrm{CDCl}_{3}\right) \delta$ ppm: $1.28(\mathrm{t}$, $\left.J=7.2 \mathrm{~Hz}, 3 \mathrm{H}, \mathrm{CH}_{2} \mathrm{CH}_{3}\right), 1.64\left(\mathrm{~m}, 6 \mathrm{H}, \mathrm{C}_{3}, \mathrm{C}_{4}, \mathrm{C}_{5}-\mathrm{H}\right.$, piperidine), $2.51\left(\mathrm{~s}, 3 \mathrm{H}, \mathrm{CH}_{3}\right), 3.42\left(\mathrm{~m}, 4 \mathrm{H}, \mathrm{C}_{2}, \mathrm{C}_{6}-\mathrm{H}\right.$, piperidine), 4.09 (q, $\left.J=7.2 \mathrm{~Hz}, 2 \mathrm{H}, \mathrm{CH}_{2} \mathrm{CH}_{3}\right), 6.11$ (s, 1H, C5-H), 6.93-7.25 (m, 5H, Ar-H), $7.52(\mathrm{~s}, 1 \mathrm{H}$, $\left.=\mathrm{CH}-\mathrm{N}\left(\mathrm{CH}_{2}\right)_{2}\right) \cdot{ }^{13} \mathrm{C} \mathrm{NMR}\left(400 \mathrm{MH}_{\mathrm{Z}}, \mathrm{CDCl}_{3}\right) \delta \mathrm{ppm}$ : 14.16, 23.02, 24.42, 26.31, 54.49, 59.84, 60.30, 100.19, $118.03,123.79-134.27,140.44,144.01,155.57$, $160.69,164.72,166.32,167.11 . \%$ CHNS found (calc): C 64.21 (64.23), H 6.12 (6.31), N 10.21 (10.37), S 7.79 (7.61).

2.7d 5-(3-Methoxy-phenyl)-7-methyl-3-oxo-2-piperidin-1-ylmethylene-2,3-dihydro-5H-thia-zolo[3,2-a]pyrimidine-6-carboxylic acid ethyl ester (7d): Pale orange red solid, yield $73 \%$, M.p.:237-238 ${ }^{\circ}$ C. IR $(\mathrm{KBr}) \quad v \quad \mathrm{~cm}^{-1}: 2945 \quad(\mathrm{CH}), 1700 \quad(\mathrm{C}=\mathrm{O}), 1611$ $(\mathrm{C}=\mathrm{C}), 1493(\mathrm{C}=\mathrm{N}), 1196(\mathrm{C}-\mathrm{O}) .{ }^{1} \mathrm{H}$ NMR (400 $\left.\mathrm{MH}_{\mathrm{Z}}, \mathrm{CDCl}_{3}\right) \delta$ ppm: $1.19(\mathrm{t}, J=7.2 \mathrm{~Hz}, 3 \mathrm{H}$, $\left.\mathrm{CH}_{2} \mathrm{CH}_{3}\right), 1.66\left(\mathrm{~m}, 6 \mathrm{H}, \mathrm{C}_{3}, \mathrm{C}_{4}, \mathrm{C}_{5}-\mathrm{H}\right.$, piperidine), 2.49 (s, $\left.3 \mathrm{H}, \mathrm{CH}_{3}\right), 3.41\left(\mathrm{~m}, 4 \mathrm{H}, \mathrm{C}_{2}, \mathrm{C}_{6}-\mathrm{H}\right.$, piperidine), 3.76 (s, $3 \mathrm{H}, \mathrm{OCH}_{3}$ ), 4.10 (q, J=7.2 Hz, $2 \mathrm{H}, \mathrm{CH}_{2} \mathrm{CH}_{3}$ ), 6.16 $(\mathrm{s}, \quad 1 \mathrm{H}, \quad \mathrm{C} 5-\mathrm{H}), \quad 6.76-7.26(\mathrm{~m}, \quad 4 \mathrm{H}, \quad \mathrm{Ar}-\mathrm{H}), \quad 7.56$ (s, $\left.1 \mathrm{H},=\mathrm{CH}-\mathrm{N}\left(\mathrm{CH}_{2}\right)_{2}\right) \cdot{ }^{13} \mathrm{CNMR}\left(400 \mathrm{MH}_{\mathrm{Z}}, \mathrm{CDCl}_{3}\right)$ $\delta$ ppm: 14.10, 22.96, 24.12, 26.54, 55.55, 57.42, 59.91, $61.10,101.12,117.53,127.12-136.19,141.19,144.23$, $155.54,161.03,163.91,166.60,167.33$. Mass (m/z): $441.8[\mathrm{M}]^{+} . \%$ CHNS found (calc): C 62.56 (62.39), H 6.16 (5.97), N 9.52 (9.38), S 7.26 (7.19).

2.7e Ethyl 3,5-dihydro-7-methyl-3-oxo-5-phenyl-2((pyrrolidin-1-yl)methylene)-2H-thiazolo [3,2-a]pyrimidine-6-carboxylate (7e): Pale orange yellow solid, yield $75 \%$, M.p.:262-263 ${ }^{\circ} \mathrm{C}$. IR (KBr) $v \mathrm{~cm}^{-1}$ : IR $\left(\mathrm{KBr} v_{\max }, \mathrm{cm}^{-1}\right): 3052,2976(\mathrm{CH}), 1707(\mathrm{C}=\mathrm{O}), 1620$ $(\mathrm{C}=\mathrm{C}), 1502(\mathrm{C}=\mathrm{N}), 1190(\mathrm{C}-\mathrm{O}) .{ }^{1} \mathrm{H} \mathrm{NMR}\left(400 \mathrm{MH}_{\mathrm{Z}}\right.$, $\left.\mathrm{CDCl}_{3}\right) \delta$ ppm: $1.22\left(\mathrm{t}, J=7.2 \mathrm{~Hz}, 3 \mathrm{H}, \mathrm{CH}_{2} \mathrm{CH}_{3}\right)$, $1.78\left(\mathrm{~m}, 4 \mathrm{H}, \mathrm{C}_{3}, \mathrm{C}_{4}-\mathrm{H}\right.$, pyrrolidine $), 2.36\left(\mathrm{~s}, 3 \mathrm{H}, \mathrm{CH}_{3}\right)$, $2.65\left(\mathrm{~m}, \mathrm{C}_{2}, \mathrm{C}_{5}-\mathrm{H}\right.$, pyrrolidine), $4.09(\mathrm{q}, J=7.2 \mathrm{~Hz}, 2 \mathrm{H}$, $\left.\mathrm{CH}_{2} \mathrm{CH}_{3}\right), 6.07$ (s, 1H, C5-H), 7.19-7.32 (m, 5H, Ar$\mathrm{H}), 7.52\left(\mathrm{~s}, 1 \mathrm{H},=\mathrm{CH}-\mathrm{N}\left(\mathrm{CH}_{2}\right)_{2}\right) \cdot{ }^{13} \mathrm{C} \mathrm{NMR}\left(400 \mathrm{MH}_{\mathrm{Z}}\right.$, $\left.\mathrm{CDCl}_{3}\right) \delta$ ppm: 14.03, 23.10, 25.31, 54.43, 59.86, 61.01, 100.17, 118.33, 123.19-135.42, 139.94, 144.21,
$155.37,160.51,164.62,166.17,167.02$. \%CHNS found (calc): C 63.45 (63.23), H 5.83 (5.67), N 10.57 (10.61), S 8.07 (7.97).

2.7f Ethyl 3,5-dihydro-5-(3-methoxyphenyl)-7-methyl3-oxo-2-((pyrrolidin-1-yl)methylene)-2H-thiazolo[3,2-a] pyrimidine-6-carboxylate $(7 \mathrm{f})$ : Pale orange yellow solid, yield $73 \%$, M.p.: $254-255^{\circ} \mathrm{C}$. IR $(\mathrm{KBr}) v \mathrm{~cm}^{-1}$ : 3048, $2977(\mathrm{CH}), 1703(\mathrm{C}=\mathrm{O}), 1618(\mathrm{C}=\mathrm{C}), 1506$ $(\mathrm{C}=\mathrm{N}), 1197(\mathrm{C}-\mathrm{O}) .{ }^{1} \mathrm{H}$ NMR $\left(400 \mathrm{MH}_{\mathrm{Z}}, \mathrm{CDCl}_{3}\right) \delta$ ppm: $1.24\left(\mathrm{t}, J=7.2 \mathrm{~Hz}, 3 \mathrm{H}, \mathrm{CH}_{2} \mathrm{CH}_{3}\right), 1.78(\mathrm{~m}, 4 \mathrm{H}$, $\mathrm{C}_{3}, \mathrm{C}_{4}-\mathrm{H}$, pyrrolidine), 2.64 ( $\mathrm{m}, \mathrm{C}_{2}, \mathrm{C}_{5}-\mathrm{H}$, pyrrolidine), $2.34\left(\mathrm{~s}, 3 \mathrm{H}, \mathrm{CH}_{3}\right), 3.79\left(\mathrm{~s}, 3 \mathrm{H}, \mathrm{OCH}_{3}\right), 4.11$ (q, $J=7.2$ $\mathrm{Hz}, 2 \mathrm{H}, \mathrm{CH}_{2} \mathrm{CH}_{3}$ ), 6.02 (s, 1H, C5-H), 6.78-7.29 (m, $4 \mathrm{H}, \mathrm{Ar}-\mathrm{H}), 7.53\left(\mathrm{~s}, 1 \mathrm{H},=\mathrm{CH}-\mathrm{N}\left(\mathrm{CH}_{2}\right)_{2}\right) .{ }^{13} \mathrm{C} \mathrm{NMR}$ $\left(400 \mathrm{MH}_{\mathrm{Z}}, \mathrm{CDCl}_{3}\right) \delta$ ppm: 14.03, 22.99, 25.51, 55.53, 57.52, 59.71, 61.23, 100.96, 118.01, 129.36-135.49, $141.02,144.19,155.37,161.29,163.71,166.32$, 167.18. \%CHNS found (calc): C 61.81 (61.67), H 5.89 (5.71), N 9.83 (9.92), S 7.50 (7.41).

\subsection{Procedure for the synthesis of tricyclic thiazolopyrimidine}

2.8a Procedure for the synthesis of ethyl 3-amino-2cyano-5-(3-methoxyphenyl)-7-methyl-5H-thiazolo[3,2a]pyrimidine-6-carboxylate (9): To a warm solution of $\mathrm{KOH}(10 \mathrm{mmol})$ and pyrimidine derivative (8) $(10 \mathrm{mmol})$ in ethanol $(30 \mathrm{~mL})$, bromomalononitrile $(11 \mathrm{mmol})$ was added dropwise with constant stirring. The reaction mixture was stirred for $2 \mathrm{~h}$. The solution was allowed to stand at room temperature for some time and the solid product precipitated. The precipitate was filtered and recrystallized from ethanol.

Yellow solid, yield 88\%, M.p.:238-239 ${ }^{\circ} \mathrm{C}$. IR (KBr) $v \mathrm{~cm}^{-1}:$ 3373, $3329\left(\mathrm{NH}_{2}\right) 2931(\mathrm{CH}), 2189(\mathrm{C} \equiv \mathrm{N})$ $1703(\mathrm{C}=\mathrm{O}), 1655(\mathrm{C}=\mathrm{C}), 1566(\mathrm{C}=\mathrm{N}), 1195(\mathrm{C}-\mathrm{O})$. ${ }^{1} \mathrm{H} \mathrm{NMR}\left(400 \mathrm{MH}_{\mathrm{Z}}, \mathrm{CDCl}_{3}\right) \delta \mathrm{ppm}: 1.25(\mathrm{t}, J=7.1 \mathrm{~Hz}$, $\left.3 \mathrm{H}, \mathrm{CH}_{2} \mathrm{CH}_{3}\right), 2.35\left(\mathrm{~s}, 3 \mathrm{H}, \mathrm{CH}_{3}\right), 3.78\left(\mathrm{~s}, 3 \mathrm{H}, \mathrm{OCH}_{3}\right)$, $4.12\left(\mathrm{q}, J=7.0 \mathrm{~Hz}, 2 \mathrm{H}, \mathrm{CH}_{2} \mathrm{CH}_{3}\right), 4.75\left(\mathrm{~s}, 2 \mathrm{H}, \mathrm{NH}_{2}\right)$, 6.06 (s, 1H, C5-H), 6.84-6.94 (m, 4H, Ar-H). ${ }^{13} \mathrm{C} \mathrm{NMR}$ $\left(400 \mathrm{MH}_{\mathrm{Z}}, \mathrm{CDCl}_{3}\right) \delta$ ppm:14.09, 23.06, 54.87, 60.06, $90.43,102.32,113.76,118.42,129.63,132.63,143.19$, 155.35, 157.99, 163.16, 164.09, 165.23. \%CHNS found (calc): C 58.36 (58.62), H 4.90 (5.06), N 15.12 (15.13), S 8.66 (8.59).

2.8b Procedure for the synthesis 2-cyano-3-(1-ethoxyethylideneamino)-5-(3-methoxy-phenyl)-7-methyl-5Hthiazolo[3,2-a]pyrimidine-6-carboxylic acid ethyl ester (10): A mixture of $9(1.85 \mathrm{~g}, 5 \mathrm{mmol})$ and triethylorthoacetate $(2 \mathrm{~mL})$ was heated under reflux in acetic anhydride for $6 \mathrm{~h}$, excess triethylorthoacetate and acetic 
anhydride was removed. The residue was treated with petroleum ether. The solid thus separated was filtered, washed and recrystallized with petroleum ether to afford light greenish yellow crystals.

Yellow green solid, yield 83\%, M.p.:110-111 ${ }^{\circ} \mathrm{C}$. IR $(\mathrm{KBr}) v \mathrm{~cm}^{-1}: 2977,2935(\mathrm{CH}), 2224(\mathrm{C} \equiv \mathrm{N})$, $1703(\mathrm{C}=\mathrm{O}), 1616(\mathrm{C}=\mathrm{C}), 1541(\mathrm{C}=\mathrm{N}), 1184(\mathrm{C}-\mathrm{O})$; ${ }^{1} \mathrm{H}$ NMR $\left(400 \mathrm{MH}_{\mathrm{Z}}, \mathrm{CDCl}_{3}\right) \delta \mathrm{ppm}: 1.21(\mathrm{t}, J=7.1$ $\mathrm{Hz}, 3 \mathrm{H}, \mathrm{CH}_{2} \mathrm{CH} 3$ ), 1.36 (t, $J=7.1 \mathrm{~Hz}, 3 \mathrm{H}, \mathrm{CH}_{2} \mathrm{CH}_{3}$ ), 1.43(s, 3H, $\left.\mathrm{CH}_{3}\right), 2.00\left(\mathrm{~s}, 3 \mathrm{H}, \mathrm{CH}_{3}\right), 2.36(\mathrm{~s}, 3 \mathrm{H}$, $\left.\mathrm{CH}_{3}\right), 3.73\left(\mathrm{~s}, 3 \mathrm{H}, \mathrm{OCH}_{3}\right), 4.08(\mathrm{q}, J=7.0 \mathrm{~Hz}, 2 \mathrm{H}$, $\left.\mathrm{CH}_{2} \mathrm{CH}_{3}\right), 4.28\left(\mathrm{q}, J=7.0 \mathrm{~Hz}, 2 \mathrm{H}, \mathrm{CH}_{2}\right), 5.94(\mathrm{~s}, 1 \mathrm{H}$, C5-H), 6.76-7.23 (m, 4H, Ar-H). ${ }^{13} \mathrm{C}$ NMR $\left(400 \mathrm{MH}_{\mathrm{Z}}\right.$, $\left.\mathrm{CDCl}_{3}\right) \delta$ ppm:14.11, 23.14, 25.08, 54.08, 54.89, 59.46, $90.48,102.30,112.89,113.05,118.68,129.63,143.17$, $155.35,158.97,159.55,163.23,164.17,165.46$. \%CHNS found (calc): C 58.96 (58.72), H 5.16 (5.33), N 11.96 (12.01), S 6.84 (7.03).<smiles>[R]OC(=O)C1=C(C)N=C2SC[CH+]C(=O)N2C1c1cccc([R])c1</smiles>

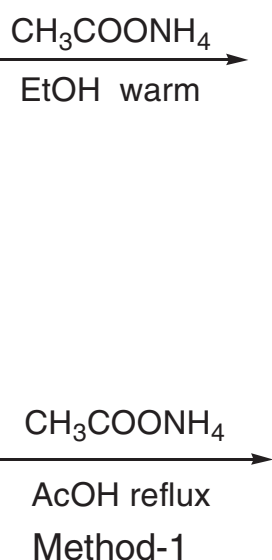

Method-1<smiles>[R]OC(=O)C1=C(C)N=c2s/c(=C\c3ccccc3OC(C)(C)C)c(=O)n2C1c1ccccc1</smiles>

\begin{tabular}{llll|llll}
\hline Code & $\mathbf{R}$ & $\mathbf{R}_{\mathbf{1}}$ & $\mathbf{R}_{\mathbf{2}}$ & Code & $\mathbf{R}$ & $\mathbf{R}_{\mathbf{1}}$ & $\mathbf{R}_{\mathbf{2}}$ \\
\hline $2 \mathrm{a}$ & $\mathrm{H}$ & $\mathrm{H}$ & $\mathrm{Et}$ & $2 \mathrm{c}$ & $4-\mathrm{OH}$ & $4-\mathrm{COOH}$ & $\mathrm{Et}$ \\
$2 \mathrm{~b}$ & $4-\mathrm{OH}$ & $3-\mathrm{CN}$ & $\mathrm{Me}$ & $2 \mathrm{~d}$ & $4-\mathrm{OH}$ & $3-\mathrm{F}$ & $\mathrm{Me}$ \\
\hline
\end{tabular}

\section{Mechanism for hydrolysis}

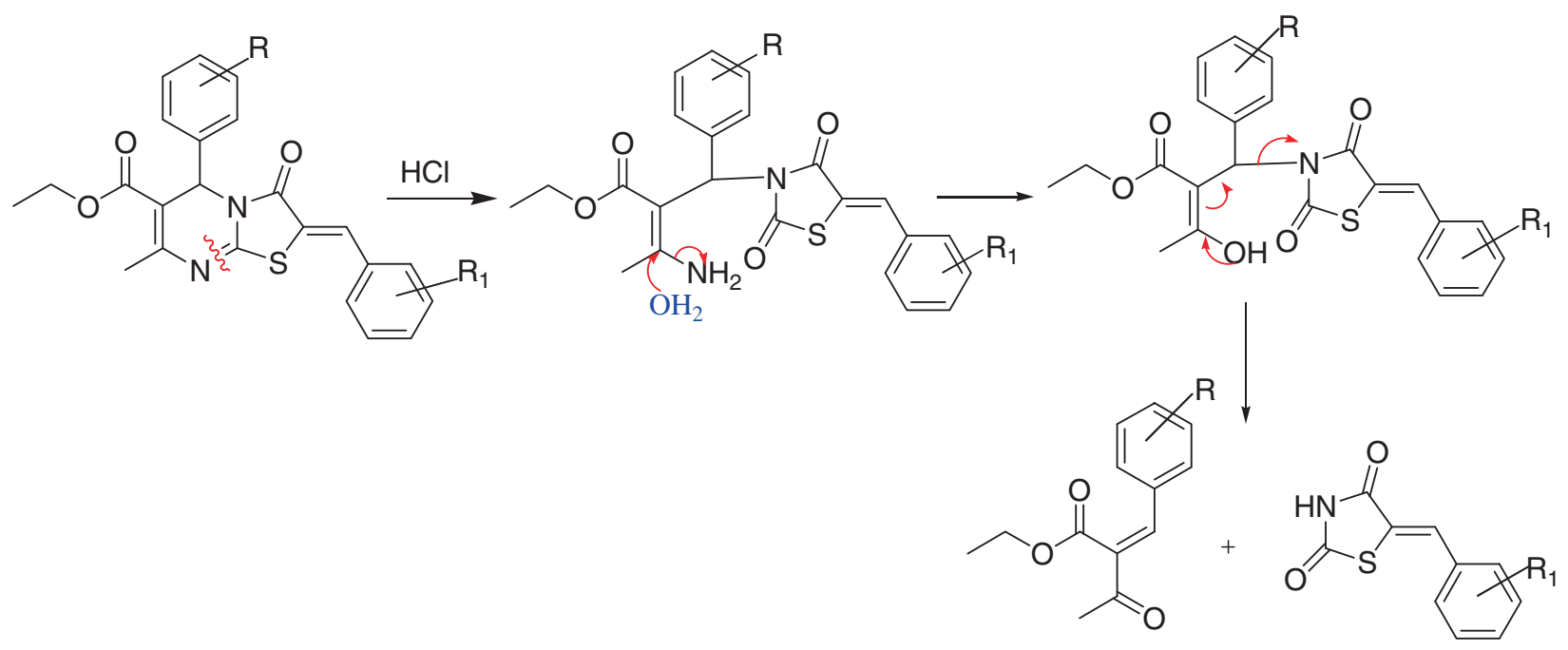

Scheme 1. Synthesis and hydrolysis of arylidene derivatives of thiazolopyrimidine. 
2.8c Procedure for the synthesis 7-amino-8-imino4-(3-methoxy-phenyl)-2,6-dimethyl-7,8-dihydro-4H-9thia-1,4a,5,7-tetraaza-fluorene-3-carboxylic acid ethyl ester (11): A mixture of $\mathbf{1 0}(2.2 \mathrm{~g}, 5 \mathrm{mmol})$ and hydrazine hydrate $(7 \mathrm{~mL})$ was stirred at room temperature for $2 \mathrm{~h}$ and then diluted with ethanol $(20 \mathrm{~mL})$. The resulting fine solid suspension was filtered, washed with ethanol and purified by recrystallization from ethanol-dioxane mixture to afford analytically (TLC) pure pale yellow granules.

Yellow solid, yield 62\%, M.p.:225-226 $6^{\circ}$. IR (KBr) $v \mathrm{~cm}^{-1}$ : $3361(\mathrm{NH}), 3232,3190\left(\mathrm{NH}_{2}\right), 2923(\mathrm{CH})$, $1697(\mathrm{C}=\mathrm{O}), 1652(\mathrm{C}=\mathrm{C}), 1492(\mathrm{C}=\mathrm{N}), 1230(\mathrm{C}-\mathrm{O})$. ${ }^{1} \mathrm{H}$ NMR $\left(400 \mathrm{MH}_{\mathrm{Z}}\right.$, DMSO- $\left.d_{6}\right) \delta$ ppm: $1.15(\mathrm{t}, J=7.2$ $\left.\mathrm{Hz}, 3 \mathrm{H}, \mathrm{CH}_{2} \mathrm{CH}_{3}\right), 2.29$ (s, 3H, $\left.\mathrm{CH}_{3}\right), 2.33$ (s, 3H, $\mathrm{CH}_{3}$ ), 3.68 (s, 3H, $\mathrm{OCH}_{3}$ ), 4.06 (q, $J=7.2 \mathrm{~Hz}, 2 \mathrm{H}$, $\left.\mathrm{CH}_{2} \mathrm{CH}_{3}\right), 4.81$ (s, 2H, NH2), 6.42 (s, 1H, C5-H of thiazolopyrimidine), 6.78-7.21 (m, 4H, Ar-H), 8.97 $(\mathrm{s}, 1 \mathrm{H},=\mathrm{NH}) .{ }^{13} \mathrm{C}$ NMR $\left(400 \mathrm{MH}_{\mathrm{Z}}, \mathrm{DMSO}-d_{6}\right) \delta \mathrm{ppm}$ : 14.11, 23.14, 25.08, 54.08, 54.89, 59.46, 90.48, 102.30, $112.89,113.05,118.68,129.63,143.17,155.35$, $158.97,159.55,163.23,164.17,165.46 . \%$ CHNS found (calc): C 56.32 (56.42), H 5.20 (4.99), N 19.70 (19.83), S 7.52 (7.59).

\section{$2.9 \quad X$-ray diffraction analysis}

Good quality single crystals of compounds $\mathbf{3}, \mathbf{5 b}$ and 7a were obtained by slow evaporation of ethanol. The X-ray diffraction data, for the compounds $\mathbf{3}$, 5b and 7a were collected on a Bruker Smart CCD Area Detector System using MoK $\alpha(0.71073 \AA$ A ) radiation. The data were reduced using SAINT-Plus. ${ }^{15}$ The structure was solved by Direct methods using SHELXS $97^{16}$ and refined by difference Fourier syntheses using SHELXL97. ${ }^{16}$ The positions and anisotropic displacement parameters of all non-hydrogen atoms were included in the full-matrix least-square refinement using SHELXL97 ${ }^{16}$ and the refinement procedures were carried out until convergence was reached.
The $\mathrm{H}$ atoms were placed at calculated positions in the riding model approximation, their temperature factors were set to 1.2 times those of the equivalent isotropic temperature factors of the parent atoms. All other non- $\mathrm{H}$ atoms were refined anisotropically. Molecular diagrams were generated using ORTEP. ${ }^{17}$ The mean plane calculation was done using the program PARST. ${ }^{18}$

\subsection{Anti-microbial activity}

Anti-microbial activities of the synthesized compounds 2d, 4a, 5a, 5b, 6a, 7a, 7d, 9 and 10 were screened against the two standard bacterial strains Staphylococcus aureus, E.coli and two standard fungal strains Aspergillus niger, Penicillium chrysogenum by Agar diffusion method with 3 different concentrations $(0.5$, $1.0,2.0 \mathrm{mg} / \mathrm{mL}) .{ }^{19,20}$

For anti-bacterial activity test, media used was peptone $10 \mathrm{~g}, \mathrm{NaCl} 10 \mathrm{~g}$ and yeast extract $5 \mathrm{~g}$, agar $20 \mathrm{~g}$ in $1000 \mathrm{~mL}$ distilled water. Initially, the stock cultures of bacteria were revived by inoculating in broth media and grown at $37^{\circ} \mathrm{C}$ for $18 \mathrm{~h}$. The agar plates of the above media were prepared and wells were made in the plate. Each plate was inoculated with $18 \mathrm{~h}$ old cultures $\left(100 \mu \mathrm{L}, 10^{-4} \mathrm{CFU}\right)$ and spread evenly on the plate. After $20 \mathrm{~min}$, the wells were filled with compound at different concentrations. The control wells with Gentamycin were also prepared. All the plates were incubated at $37^{\circ} \mathrm{C}$ for $24 \mathrm{~h}$ and the diameter of inhibition zone were noted.

For anti-fungal activities media used was CzapekDox Agar: Composition (g/L) Sucrose-30.0; Sodium nitrate-2.0; $\mathrm{K}_{2} \mathrm{HPO}_{4}-1.0, \mathrm{MgSO}_{4}$. 7 $\mathrm{H}_{2} \mathrm{O}-0.5 ; \mathrm{KCl}-0.5$; $\mathrm{FeSO}_{4}-0.01$; Agar-20: Initially, the stock cultures offungi were revived by inoculating in broth media and grown at $27^{\circ} \mathrm{C}$ for $48 \mathrm{~h}$.

The agar plates of the above media were prepared and wells were made in the plate. Each plate was<smiles>[R]c1cccc(C2C(C(=O)OCC)=C(C)N=C3SC(CN4CCOCC4)C(=O)N3C2c2cccc([R])c2)c1</smiles>

Scheme 2. Synthesis of some new derivatives of thiazolopyrimidines. 
inoculated with $48 \mathrm{~h}$ old cultures $\left(100 \mu \mathrm{L}, 10^{4} \mathrm{CFU}\right)$ and spread evenly on the plate. After $20 \mathrm{~min}$, the wells were filled with different concentrations of samples. The control wells were filled with antibiotic. All the plates were incubated at $27^{\circ} \mathrm{C}$ for $72 \mathrm{~h}$ and the diameter of inhibition zone were noted. The results of the anti-microbial activities are shown in table 3.

\section{Result and Discussion}

\subsection{Chemistry}

Compounds were synthesized by following procedure depicted in the schemes $1,2,3$ and 4 . The starting materials 7-methyl-3-oxo-5-(substituted phenyl)-2,3dihydro-5H-thiazolo[3,2-a]pyrimidine-6-carboxylic acid
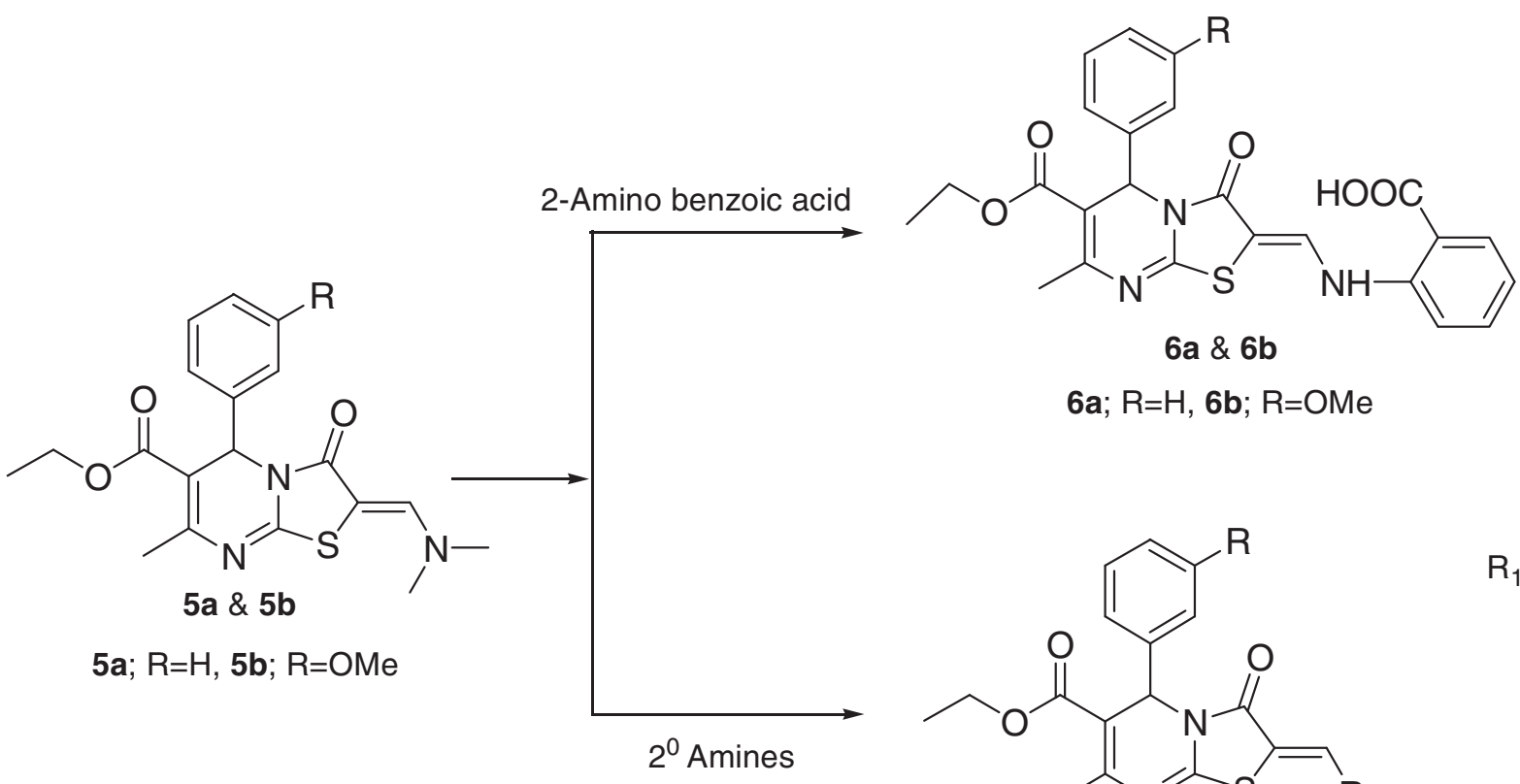

6a; $\mathrm{R}=\mathrm{H}, \mathbf{6 b} ; \mathrm{R}=\mathrm{OMe}$<smiles>C1COCCN1</smiles><smiles>[R7]C=c1sc2n(c1=O)C(c1cccc([R])c1)C(C(=O)OCC)=C(C)N=2</smiles>
$\mathrm{R}_{1}=$<smiles>C1CCNCC1</smiles><smiles>C1CCNC1</smiles>

$\mathrm{R}=\mathrm{H}, \mathrm{OMe}$

Scheme 3. Synthesis of dimethyl amino-methylene derivatives of thiazolopyrimidines.<smiles>CCOC(=O)C1=C(C)NC(=S)NC1c1cccc(OC)c1</smiles>

8

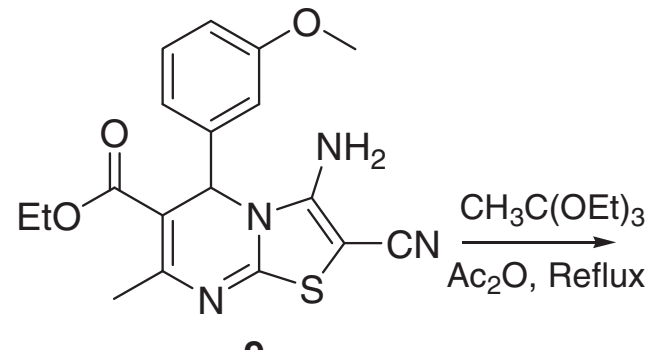

9<smiles>CCOC(=O)C1=C(C)N=C2SC(C#N)=C(/N=C(\C)OCC)N2C1c1cccc(OC)c1</smiles>

10<smiles>CCOC(=O)C1=C(C)N=C2Sc3c(nc(C)n(N)c3=N)N2C1c1cccc(OC)c1</smiles>

Scheme 4. Synthesis of tricyclic thiazolopyrimidine. 
ethyl esters 1(a-e) were prepared by treating 6-methyl4-(substituted phenyl)-2-thioxo-1,2,3,4-tetrahydro-pyrimidine-5-carboxylic acid ethyl esters with chloro acetic acidin dioxane under reflux condition. These active methylene compounds 1a, 1d and 1e were further allowed to react with substituted aromatic aldehydes in presence of ammonium acetate to givearylidene derivatives of thiazolopyrimidine. The ${ }^{1} \mathrm{H}$ NMR spectra of compounds $\mathbf{2}(\mathbf{a}-\mathbf{d})$ indicate the absence of signals for the $\mathrm{CH}_{2}$ proton around $\delta 3.7-3.9 \mathrm{ppm}$ and additional signals in the aromatic region. Acid hydrolysis of arylidene derivative 2a leads to the formation of thiazolid-2,4-one (3) via the rupture of endocyclic $\mathrm{C}=\mathrm{N}$ bond in pyrimidine ring by method $\mathbf{1}$. The hydrolyzed component (3) was also obtained by an alternative method 2, which involves in situ condensation followed by hydrolysis (scheme 1 ).

Compounds 1a and $\mathbf{1 b}$ undergo Mannich reaction with different secondary amines yielding compounds 4a and $\mathbf{4 b}$. Further treatment of compounds $1(\mathbf{a}-\mathbf{d})$ with dimethylformamide-dimethylacetal (DMF-DMA) under reflux condition gave 2-dimethylaminomethylene7-methyl-3-oxo-5-(substituted phenyl)-2,3-dihydro-5 $\mathrm{H}$ thiazolo[3,2- $a$ ]pyrimidine-6-carboxylic acid ethyl esters
5 (a-d). In order to confirm the spectral data, one of the derivative $\mathbf{5 b}$ was subjected to single crystal X-ray diffraction technique. Crystal structure of compound $\mathbf{5 b}$ showed that the product is $Z$-isomer. Treatment of compounds $\mathbf{5} \mathbf{a}$ and $\mathbf{5} \mathbf{b}$ with 2 -amino benzoic acid gave the corresponding secondary amine derivative. Reaction of compounds $\mathbf{5 a}$ and $\mathbf{5 b}$ with secondary amines likes morpholine, piperidine or pyrrolidine taken in ethanol, on refluxing gave corresponding tertiaryamines 7 (a-f) (scheme 2). In addition to spectral technique, one of the tertiary amine was subjected to single crystal X-ray diffraction technique. Crystal structure of compound 7a showed the morpholine ring adopts chair conformation.

Compound $\mathbf{8}$ was synthesized from well-known Biginelli one pot cyclo-condensation reaction. ${ }^{21}$ The reaction of dihydropyrimidine $(\mathbf{8})$ with bromomalononitrile in presence of strong base resulted in the formation of compound 9. Product was confirmed by using spectral techniques. In the IR spectrum of compound 9 there is an appearance of sharp peak at $2189 \mathrm{~cm}^{-1}$ characteristic of nitrile group and two sharp peaks at $3300-3150 \mathrm{~cm}^{-1}$ correspond to $-\mathrm{NH}_{2}$ group and in the ${ }^{1} \mathrm{H}$ NMR spectrum, appearance of signal at $\delta 4.75 \mathrm{ppm}$ correspond to $-\mathrm{NH}_{2}$ confirming ring closure. Compound

Table 1. Crystal data and refinement parameters for compounds $\mathbf{3}, \mathbf{5 b}$ and $\mathbf{7 a}$.

\begin{tabular}{|c|c|c|c|}
\hline & 3 & $5 \mathbf{b}$ & $7 \mathbf{a}$ \\
\hline Formula & $\mathrm{C}_{10} \mathrm{H}_{7} \mathrm{NO}_{2} \mathrm{~S}$ & $\mathrm{C}_{20} \mathrm{H}_{23} \mathrm{~N}_{3} \mathrm{O}_{4} \mathrm{~S}$ & $\mathrm{C}_{21} \mathrm{H}_{23} \mathrm{~N}_{3} \mathrm{O}_{4} \mathrm{~S}$ \\
\hline M & 205.23 & 401.47 & 413.48 \\
\hline$T / \mathrm{K}$ & $296(2)$ & $296(2)$ & $296(2)$ \\
\hline Crystal system & Monoclinic & Monoclinic & Monoclinic \\
\hline Space group & $P 2_{1} / \mathrm{c}$ & $P 2_{1} / \mathrm{c}$ & $P 2_{1} / \mathrm{c}$ \\
\hline$a / \AA$ & $9.4365(6)$ & $15.4787(17)$ & $12.3736(13)$ \\
\hline$b / \AA$ & $11.5294(8)$ & $9.6946(11)$ & $12.2454(13)$ \\
\hline$c / \AA ̊$ & $8.1876(6)$ & $13.0224(14)$ & $13.0093(13)$ \\
\hline$\beta /\left({ }^{\mathrm{o}}\right)$ & $95.5990(10)$ & $90.836(2)$ & $99.458(2)$ \\
\hline$V / \AA^{3}$ & $886.54(11)$ & $1953.9(4)$ & $1944.4(3)$ \\
\hline $\mathrm{Z}, d_{\text {calcd }} /\left(\mathrm{g} \mathrm{cm}^{-3}\right)$ & $4,1.538$ & $4,1.365$ & $4,1.413$ \\
\hline$\mu / \mathrm{mm}^{-1}$ & 0.332 & 0.198 & 0.201 \\
\hline$F(000)$ & 424 & 848 & 872 \\
\hline$\theta$ range $/\left({ }^{\circ}\right)$ & 2.80 to 25.00 & 1.32 to 27.00 & 1.67 to 27.00 \\
\hline \multirow[t]{3}{*}{ Index ranges } & $-11<=\mathrm{h}<=11$ & $-15<=\mathrm{h}<=19$ & $-13<=\mathrm{h}<=15$ \\
\hline & $-13<=\mathrm{k}<=13$ & $-12<=\mathrm{k}<=12$ & $-14<=\mathrm{k}<=15$ \\
\hline & $-9<=1<=7$ & $-15<=1<=16$ & $-16<=1<=8$ \\
\hline Reflections collected & 4506 & 11280 & 11413 \\
\hline Independent & 1554 & 4209 & 4197 \\
\hline reflections & {$\left[\mathrm{R}_{\mathrm{int}}=0.0214\right]$} & {$\left[\mathrm{R}_{\mathrm{int}}=0.0386\right]$} & {$\left[\mathrm{R}_{\mathrm{int}}=0.0356\right]$} \\
\hline Completeness & $99.4 \%$ & $98.5 \%$ & $98.8 \%$ \\
\hline Data/restraints/parameters & $1554 / 0 / 127$ & $4209 / 0 / 258$ & $4197 / 0 / 264$ \\
\hline Goodness-of-fit on $F^{2}$ & 0.940 & 1.499 & 0.949 \\
\hline$R_{1}, w R_{2}[I>2 \sigma(I)]$ & $0.0347,0.0998$ & $0.0671,0.1763$ & $0.0619,0.1644$ \\
\hline$R_{1}, w R_{2}$ (all data) & $0.0369,0.1059$ & $0.0966,0.2502$ & $0.0865,0.2418$ \\
\hline $\begin{array}{l}\text { Largest diff. peak, } \\
\left.\text { hole/(e } \mathrm{A}^{-3}\right)\end{array}$ & $0.266,-0.363$ & $0.947,-0.774$ & $0.751,-0.761$ \\
\hline
\end{tabular}


9 and triethylorthoacetate was refluxed in acetic anhydride to give compound 10. IR spectrum shows the absence of peaks around 3300-3150 $\mathrm{cm}^{-1}$ confirming the absence of $-\mathrm{NH}_{2}$ group and from the ${ }^{1} \mathrm{H}$ NMR spectrum appearance of signals at $\delta 1.36,1.45$ and $4.28 \mathrm{ppm}$ corresponds to additional $-\mathrm{CH}_{3},-\mathrm{CH}_{3}$ and $-\mathrm{CH}_{2}$ groups respectively. Further treatment of compound 10 with hydrazine hydrate in ethanol gave tricyclic thiazolopyrimidine $\mathbf{1 1}$. The ring system obtained was confirmed by IR spectrum. The absence of peak at $2189 \mathrm{~cm}^{-1}$ indicates that there is nonitrile group, the appearance of peak at 3361 and peaks at 3232 and $3190 \mathrm{~cm}^{-1}$ corresponds to $-\mathrm{NH}$ and $-\mathrm{NH}_{2}$ group.

\subsection{Crystallography}

The details of crystal data and refinements are given in table 1 for the compounds $\mathbf{3}, \mathbf{5 b}$ and $\mathbf{7 a}$. Tables $\mathbf{2 a}$ and $\mathbf{2 b}$ give respective hydrogen bond interactions. The ORTEP view of the molecule with atomic labeling (thermal ellipsoids drawn at $50 \%$ probability) of $\mathbf{3}, \mathbf{5 b}$ and $7 \mathbf{a}$ are shown in figures $1,2 \mathrm{a}$ and $2 \mathrm{~b}$ respectively. Figures $3 \mathrm{a}, 3 \mathrm{~b}$ and $3 \mathrm{c}$ show the packing of molecules in the crystal structure.

Compounds $\mathbf{5 b}$ and $\mathbf{7 a}$ crystallize in the monoclinic space group containing one molecule each in the asymmetric unit. Both the compounds have almost similar substituents at C2, C3, C5, C6 and C7. In compounds $\mathbf{5 b}$ and $\mathbf{7 a}$, the aryl ring at $\mathrm{C} 5$ is positioned axially to the pyrimidine ring $^{22}$ with a dihedral angle of $89.88(8)$ and $89.66(8)^{\circ}$ respectively. Aryl ring in both the compounds is projecting away from the plane of the thiazolopyrimidine ring. The ethyl carboxylate group at $\mathrm{C6}$ in compound 7a is planar with respect to the thiazolopyrimidine ring whereas in compound $\mathbf{5 b}$

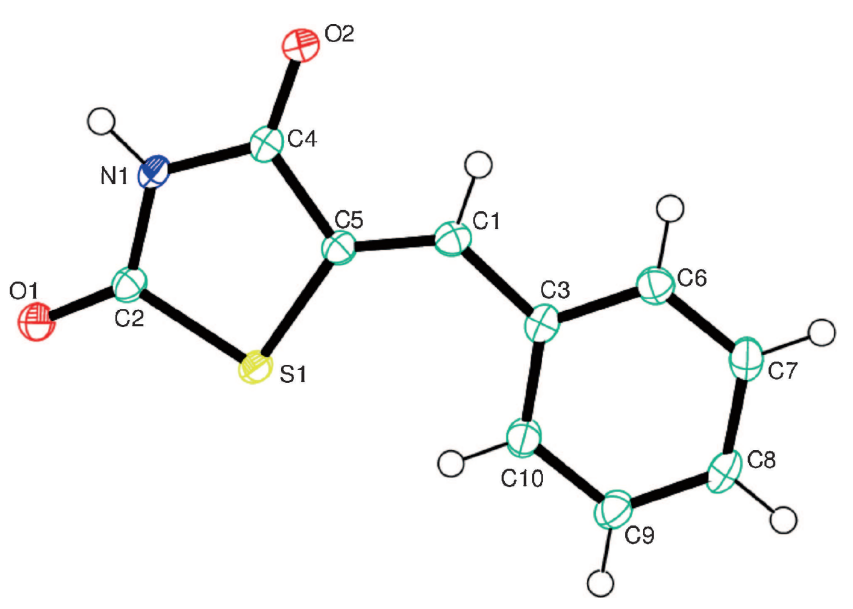

Figure 1. ORTEP diagram for the hydrolyzed compound $\mathbf{3}$.

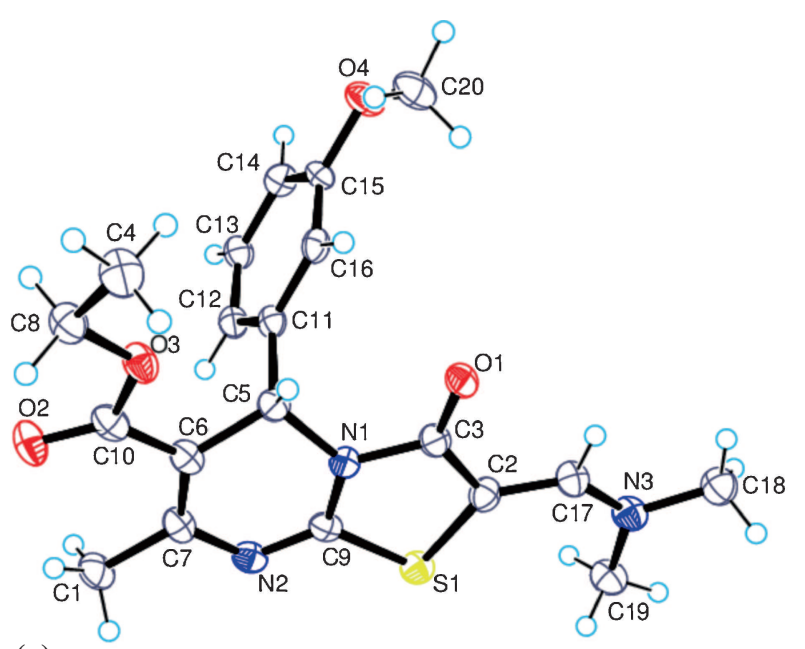

(a)

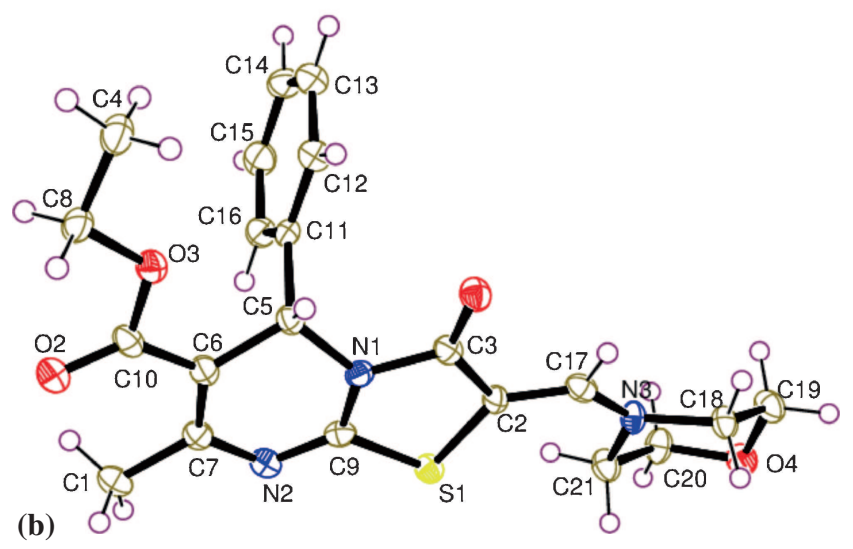

Figure 2. (a) ORTEP view of compound $\mathbf{5 b}$, showing $50 \%$ probability ellipsoids and the atom numbering scheme. (b) ORTEP view of compound 7a, showing $50 \%$ probability ellipsoids and the atom numbering scheme.

it slightly deviates from the mean plane of thiazolopyrimidine with dihedral angle of $17.77(8)^{\circ}$ this may be attributed to the presence of bulky group at C5. The centralpyrimidine ring in compounds $\mathbf{5 b}$ and $\mathbf{7 a}$ adopt twist boat conformation ${ }^{22}$ due to the deviation of $\mathrm{C} 5$ and $\mathrm{N} 2$ atom from the mean plane $\mathrm{C} 6 / \mathrm{C} 7 / \mathrm{C} 9 / \mathrm{N} 1$ constituting ring by $-0.295 /-0.297(3)$ and $-0.052 /-0.066(3) \AA$ respectively. The two values separated by '/' correspond to two different compounds i.e. $\mathbf{5 b}$ and $\mathbf{7 a}$. In compound $\mathbf{5 b}$, dimethylaminomethylene group adopts $\mathrm{Z}$ configuration. The substituted morpholine ring at $\mathrm{C} 17$ of compound 7a adopts chair conformation with the atoms $\mathrm{N} 3$ and $\mathrm{O} 4$ displaced from the mean plane of the remaining ring atoms $(\mathrm{C} 18 / \mathrm{C} 19 / \mathrm{C} 20 / \mathrm{C} 21)$ by 0.6863 (2) and -0.5735 (2) $⿱$ Á, respectively.

The crystal structure of the compound $\mathbf{5 b}$ is stabilized by C-H. . O and C-H. . . N interactions. There are two types of C-H. . O interactions, the former C8H8A...O4 interaction running along crystallographic ' $b$ ' axis, whereas the later $\mathrm{C} 12-\mathrm{H} 12$...O1 interaction 
running along crystallographic 'c' axis. Both resulted in two dimensional networks. The C-H. . .N interaction generates bifurcated bonds from two donors, $\mathrm{C} 17$ and $\mathrm{C} 18$, to the same acceptor $\mathrm{N} 2$ along 'c' axis. The crystal structure is further stabilized by $\mathrm{C} 4-\mathrm{H} 4 \mathrm{~B}$. . . Cg1 $(\mathrm{Cg} 1$ is the centroid of aryl ring $\mathrm{C} 11-\mathrm{C} 16)$ interaction with a distance of $2.842 \AA$ (table 2a).

The crystal structure of the compound $7 \mathbf{a}$ is also stabilized by C-H. .. O and C-H. .. N interactions. As in the case of compound $\mathbf{5 b}$ there are two types of $\mathbf{C}$ $\mathrm{H}$. . .O interactions. Here one of the C-H. . O interaction generates bifurcated bonds from two donors, $\mathrm{C} 4$ and $\mathrm{C} 14$, to the same acceptor $\mathrm{O} 4$ along ' $\mathrm{a}$ ' axis. The other two interactions $\mathrm{C}-\mathrm{H}$. . .O and $\mathrm{C}-\mathrm{H}$. . .N are resulting in a helical pattern running along the ' $b$ ' axis (figure 3c). The crystal structure is also stabilized by $\mathrm{C} 19-\mathrm{H} 19 \mathrm{~B} \ldots \mathrm{Cg} 2(\mathrm{Cg} 2$ is the centroid of aryl ring (11-C16) interaction with a distance of $2.940 \AA$ '

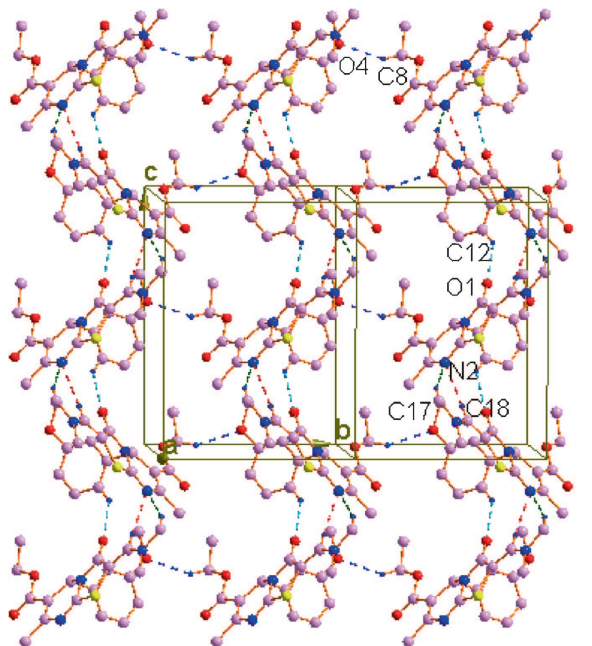

(a)

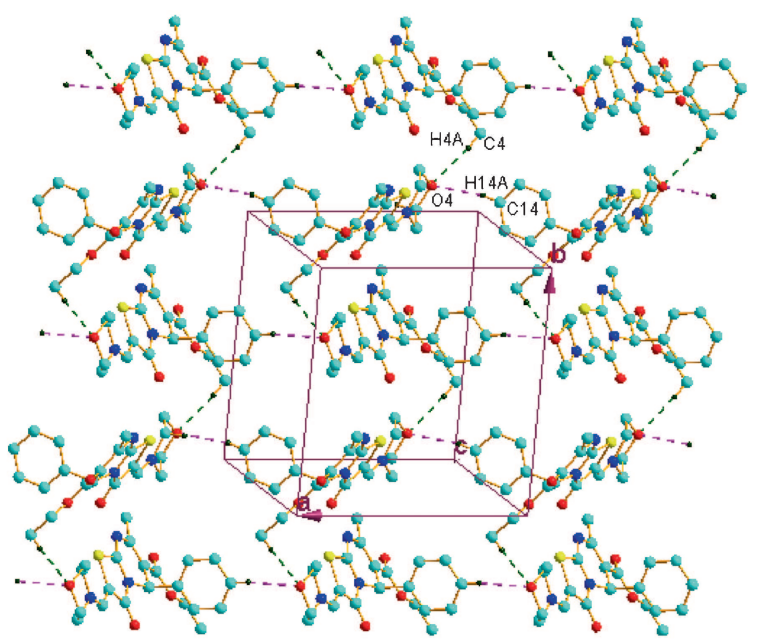

(b)

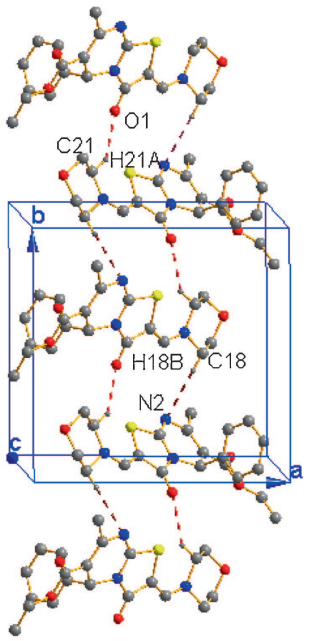

(c)

Figure 3. (a) Packing of the compound 5b showing intermolecular C-H...O and C-H...N interactions. (b) Packing of the compound 7a showing intermolecular bifurcated $\mathrm{C}-\mathrm{H}$...O interactions. (c) Packing of the compound 7a showing intermolecular C-H. . .O and C-H. . . N interactions.

Table 2a. $\quad \mathrm{C}-\mathrm{H} . . \pi$ interaction and possible hydrogen bond distances and angles $\left(\AA{ }^{\circ}\right)$ for compound $5 \mathrm{~b}(D-d o n o r ; A$ acceptor; H-hydrogen).

\begin{tabular}{lllll}
\hline $\mathbf{D}-\mathbf{H} \cdots \mathbf{A}$ & $\mathbf{D}-\mathbf{H}$ & $\mathbf{H} \cdots \mathbf{A}$ & $\mathbf{D} \cdots \mathbf{A}$ & $\mathbf{D}-\mathbf{H} \cdots \mathbf{A}$ \\
\hline $\mathrm{C} 8-\mathrm{H} 8 \mathrm{~A} \ldots \mathrm{O} 4^{\mathrm{i}}$ & 0.970 & 2.428 & $3.302(4)$ & 150 \\
$\mathrm{C} 12-\mathrm{H} 12 \ldots \mathrm{O} 1^{\mathrm{ii}}$ & 0.930 & 2.537 & $3.288(4)$ & 138 \\
$\mathrm{C} 18-\mathrm{H} 18 \mathrm{~A} \ldots \mathrm{N} 2^{\mathrm{iii}}$ & 0.970 & 2.725 & $3.639(5)$ & 159 \\
$\mathrm{C} 17-\mathrm{H} 17 \ldots$ N2 $^{\mathrm{iv}}$ & 0.930 & 2.554 & $3.470(4)$ & 168 \\
$\mathrm{C} 4-\mathrm{H} 4 \mathrm{~B} \ldots \mathrm{C}_{\mathrm{g} 1}$ & 0.960 & 2.842 & $3.733(4)$ & 155
\end{tabular}

Symmetry code: (i) $\mathrm{x},+\mathrm{y}-1,+\mathrm{z}$ (ii) $\mathrm{x},-\mathrm{y}+1 / 2,+\mathrm{z}+1 / 2$ (iii) $\mathrm{x},-\mathrm{y}+1 / 2,+\mathrm{z}-1 / 2$ (iv) $\mathrm{x},-\mathrm{y}+1 / 2,+\mathrm{z}-1 / 2(\mathrm{v})$ $\mathrm{x}, 1 / 2-\mathrm{y}, \mathrm{z}-1 / 2$

Table 2b. $\quad$ C-H. . . $\pi$ interaction and possible hydrogen bond distances and angles $\left(\AA,^{\circ}\right)$ for compound 7 a $(D-d o n o r ; A$ acceptor; H-hydrogen).

\begin{tabular}{lllll}
\hline $\mathbf{D}-\mathbf{H} \cdot \mathbf{A}$ & $\mathbf{D}-\mathbf{H}$ & $\mathbf{H} \cdots \mathbf{A}$ & $\mathbf{D} \cdots \mathbf{A}$ & $\mathbf{D}-\mathbf{H} \cdot \mathbf{A}$ \\
\hline $\mathrm{C} 21-\mathrm{H} 21 \mathrm{~A} \ldots \mathrm{OO} 1^{\mathrm{i}}$ & 0.970 & 2.670 & $3.499(4)$ & 144 \\
$\mathrm{C} 14-\mathrm{H} 14 \mathrm{~A} \ldots \mathrm{O} 4^{\mathrm{ii}}$ & 0.930 & 2.566 & $3.477(4)$ & 166 \\
$\mathrm{C} 18-\mathrm{H} 18 \mathrm{~B} \ldots 2^{\mathrm{iii}}$ & 0.970 & 2.684 & $3.653(4)$ & 177 \\
$\mathrm{C} 4-\mathrm{H} 4 \mathrm{~A} \ldots \mathrm{O} 4^{\text {iii }}$ & 0.960 & 2.577 & $3.534(4)$ & 174 \\
$\mathrm{C} 19-\mathrm{H} 19 \mathrm{~B} \ldots \mathrm{C}_{\mathrm{g} 2}$ & 0.969 & 2.940 & $3.715(4)$ & 137 \\
\hline
\end{tabular}

Symmetry code: (i) $-\mathrm{x}+1,+\mathrm{y}-1 / 2,-\mathrm{z}+1 / 2$ (ii) $\mathrm{x}+1,+\mathrm{y},+\mathrm{z}$ (iii) $-\mathrm{x}+1,+\mathrm{y}+1 / 2,-\mathrm{z}+1 / 2($ iv) $1-\mathrm{x}, 1-\mathrm{y}, 1-\mathrm{z}$ 
Table 3. Inhibition zone diameter ( $\mathrm{mm}$ ) of synthesized compounds against testedbacterial strains by Agar diffusion method.

\begin{tabular}{|c|c|c|c|c|c|c|c|c|c|c|c|c|}
\hline \multirow{3}{*}{$\begin{array}{l}\text { Compounds } \\
\text { Sample concentration }\end{array}$} & \multicolumn{6}{|c|}{ Bacteria } & \multicolumn{6}{|c|}{ Fungi } \\
\hline & \multicolumn{3}{|c|}{ E.coli } & \multicolumn{3}{|c|}{ S. aureus } & \multicolumn{3}{|c|}{ A. niger } & \multicolumn{3}{|c|}{ P. crysogenium } \\
\hline & $\overline{0.5 \mathrm{mg}}$ & $1 \mathrm{mg}$ & $2 \mathrm{mg}$ & $\overline{0.5 \mathrm{mg}}$ & $1 \mathrm{mg}$ & $2 \mathrm{mg}$ & $0.5 \mathrm{mg}$ & $1 \mathrm{mg}$ & $2 \mathrm{mg}$ & $\overline{0.5 \mathrm{mg}}$ & $1 \mathrm{mg}$ & $2 \mathrm{mg}$ \\
\hline $2 d$ & - & - & - & - & - & - & - & - & - & - & - & - \\
\hline $4 a$ & 7 & 10 & 17 & 4 & 5 & 7 & - & - & - & - & - & - \\
\hline $5 \mathrm{a}$ & - & - & - & - & - & - & - & - & - & - & - & - \\
\hline $5 b$ & - & - & - & - & - & - & - & - & - & - & - & - \\
\hline $6 \mathrm{a}$ & 0 & 3 & 5 & 0 & 2 & 3 & - & - & - & - & - & - \\
\hline $7 \mathrm{a}$ & - & - & - & - & - & - & 0 & 1 & 3 & - & - & - \\
\hline $7 \mathrm{~d}$ & - & - & - & - & - & - & - & - & - & - & - & - \\
\hline 9 & - & - & - & - & - & - & - & - & - & - & - & - \\
\hline 10 & - & - & - & 0 & 2 & 5 & - & - & - & - & - & - \\
\hline & $200 \mu \mathrm{g}$ & $400 \mu \mathrm{g}$ & $800 \mu \mathrm{g}$ & $200 \mu \mathrm{g}$ & $400 \mu \mathrm{g}$ & $800 \mu \mathrm{g}$ & $200 \mu \mathrm{g}$ & $400 \mu \mathrm{g}$ & $800 \mu \mathrm{g}$ & $200 \mu \mathrm{g}$ & $400 \mu \mathrm{g}$ & $800 \mu \mathrm{g}$ \\
\hline Gentamicin & 2.6 & 2.8 & 3.1 & 2.5 & 2.7 & 3.4 & ND & ND & ND & ND & ND & ND \\
\hline Amphotericin & ND & ND & ND & ND & ND & ND & 3 & 5 & 7 & 0 & 3 & 5 \\
\hline
\end{tabular}

Note: "-" Not Active, "ND” - Not Determined.

(table 2b). Finally, supramolecular assembly is further consolidated by $\pi-\pi$ stacking interactions between the thiazolopyrimidine rings. This interaction is not observed in the case of compound $\mathbf{5} \mathbf{b}$.

\subsection{Anti-microbial evaluation}

The anti-microbial screening was done using agar diffusion method using different strains of bacteria and fungi. The results with the test compounds $\mathbf{2 d}, \mathbf{4 a}, \mathbf{5 a}$, 5b, 6a, 7a, 7d, 9 and 10 reveal that only few compounds exhibit antimicrobial activity. Gentamicin and Amphotericin were used as reference to evaluate the potency of tested compounds. Compounds $\mathbf{6 a}, \mathbf{7 a}$ and $\mathbf{1 0}$ showed moderate anti-microbial activity, while compound $\mathbf{4 a}$ showed very good activity even at low concentration. Compounds 2d, 5a, 5b, 7d and $\mathbf{9}$ did not show any activity against the tested microorganisms. The result of anti-microbial activity is tabulated in table 3.

\section{Conclusion}

This work reports the synthesis of a new series of thiazolopyrimidines. We have developed a new and convenient synthetic method for the preparation of arylidene derivatives of thiazolopyrimidine. During our studies with thiazolopyrimidines, we have also noticed that hydrolysis of arylidene derivative of thiazolopyrimidine via rupture of endocyclic $\mathrm{C}=\mathrm{N}$ bonds in pyrimidine ring under acidic condition gives the same product as that obtained by in situ condensation followed by hydrolysis (scheme 1, method 1), for which a mechanism has been proposed. The structures of the products were confirmed by spectral techniques. In addition, crystal structures of two of the derivatives that yielded good quality crystals were verified by single crystal X-ray diffraction. Crystal structures reveal that compounds $\mathbf{5 b}$ and $\mathbf{7 a}$ are $Z$-isomers. Crystal structure of compound 7a showed the substituted morpholine ring adopts chair conformation. In both the derivatives, the ester at $\mathrm{C} 6$ adopts cis configuration with respect to $\mathrm{C} 6-\mathrm{C} 7$ double bond, which is a prerequisite for the molecule to exhibit calcium channel modulatory activity. ${ }^{23}$ On screening all the compounds, only compounds 4a, 6a, 7a, 9 and 10 exhibited good anti-microbial activities at very low concentration of 0.5-2.0 mg/mL against Aspergillus niger, Penicillium chrysogenum, Staphylococcus aureus and Escherichia coli. using Gentamicin and Amphotericin as standards.

\section{Supplementary Information}

The CIF files are deposited at the Cambridge Crystallographic Data Centre. The deposition number of compounds $\mathbf{3}, \mathbf{5 b}$ and $\mathbf{7 a}$ are CCDC-966410, CCDC-975896 and CCDC-975899, respectively.

\section{Acknowledgements}

NSB and HN thank the University Grants Commission, New Delhi, India for the financial assistance.

\section{References}

1. Abu-Hashem A A, Gouda MA and Badria FA 2010 Eur. J. Med. Chem. 451976

2. Youssef M S K, Ahmed R A, Abbady M S, AbdelMohsen S A and Omar A A 2008 Monatsh Chem. 139553 
3. Sayed H H, Morsy E M H and Kotb E R 2010 Synth. Commun. 402712

4. Yaragatti N B, Kulkarni M V, Ghate M D, Hebbar S S and Hegde G R 2010 J. Sulfur Chem. 31 123

5. Fatima S, Sharma A, Saxena R, Tripathi R, Shukla S K, Pandey S K, Tripathi R and Tripathi R P 2012 Eur. J. Med. Chem. 55195

6. Abu-Hashem A A, Youssef M M and Husseina H A R 2011 J. Chin. Chem. Soc. 5841

7. Alam O, Khan S A and Ahsan N S W 2010 Med. Chem. Res. 191245

8. Jean Kumar V U, Poyraz O, Saxena S, Schnell R, Yogeeswari P, Schneider G and Sriram D 2013 Bioorg. Med. Chem. Lett. 231182

9. Mohamed A M, Amr A E, Alsharari M A, Al-Qalawi H R M, Germoush M O and Al-Omar M A 2011 Am. J. Biochem. \& Biotech. 743

10. Fatmah A M, Al-Omary, Hassan G S, El-Messery S M and El-Subbagh H I 2012 Eur. J. Med. Chem. 47 65

11. Amr A E E, Maigali S S and Abdulla M M 2008 Monatsh Chem. 1391409

12. Flefel E E, Salama M A and Shahat M E 2007 Phosphorus, Sulfur Silicon Relat. Elem. 1821739

13. Hu J, Wang Y, Wei X, Wu X, Chen G, Cao G, Shen X, Zhang X, Tang Q, Liang G and Li X 2013 Eur. J. Med. Chem. 64292
14. Kotaiah Y, Hari Krishna N, Naga Raju K, Rao C V, Jonnalagadda S B, Maddila S 2012 J. Korean. Chem. Soc. 5668

15. Bruker. SMART. SAINT-Plus. SADABS. Bruker AXS Inc. Madison, 1998

16. Sheldrick G M 2008 Acta. Cryst. A 64112

17. Farrugia L J, ORTEP-3. 1999 J. Appl. Cryst. 32837

18. Nardelli M 1983 Acta Cryst. C 391141

19. Threlfall E J, Fisher I S T, Ward L, Tschape H and Gerner-Smidt P 1999 Microb. Drug Resist. 5195

20. Walker R D 2000 In Antimicrobial Therapy in Veterinary Medicine J F Prescott, J D Baggot and R D Walker (Eds.) (Ames, IA: Iowa State University Press) p. 12

21. (a) Biginelli P 1891 Ber. 24 1317; (b) Biginelli P 1893 Ber. 26 447; (c) Biginelli P 1893 Gazz. Chim. Ital. 23 360

22. (a) Nagarajaiah H, Khazi I M and Begum N S 2012 J. Chem. Sci. 124 847; (b) Nagarajaiah H and Begum N S 2012 Acta Cryst. E 68 o2878; (c) Nagarajaiah H, Fathima N and Begum N S 2012 Acta Cryst. E 68 o1257; (d) Nagarajaiah H and Begum N S 2011 Acta Cryst. E 67 o3444

23. (a) Rovnyak G C, Kimball S D, Beyer B, Cucinotta G, DiMarco J D, Gougoutas J, Hedberg A, Malley M, McCarthy J P, Zhang R and Moreland S 1995 J. Med. Chem. 38 119; (b) Triggle D J and Padmanabhan S 1995 Chemtracts: Org. Chem. 8191 